\section{(D) Check for updates}

Cite this: Polym. Chem., 2021, 12 ,

1329

DOI: 10.1039/d1py90028e

rsc.li/polymers

\title{
Pioneering investigators 2021
}

\author{
Holger Frey (iD ${ }^{a}$ and Emily Pentzer (iD ${ }^{b}$
}

This collection gathers the very best work from mid-career researchers who have firmly established themselves in the field of polymer chemistry and continuously publish creative, innovative work. The 2021 Polymer Chemistry pioneering investigators were individually nominated by members of the journal Editorial and Advisory Boards, and previous pioneering investigators, in recognition of their achievements as pioneers of the field. The diversity of the research topics highlighted by these contributions illustrates the broad impact of polymer chemistry across science and engineering.

We were overwhelmed by the positive response we received to our invitation to contribute to this collection. We received almost 90\% immediate acceptance of our invitation to publish in this volume, despite the Covid-19 pandemic leading to the shut down of laboratories and limited access to some resources.

During their mid-career, many researchers choose to redefine the longterm objectives of their research programs, to establish challenging and highrisk topics as well as more extensive research programs covering a whole subfield of importance. When the pressure and insecurity of the first career stage has waned, one has more freedom to define research directions and get immersed in new ventures. In this respect, this collection can also be understood as a kind of

\footnotetext{
${ }^{a}$ Johannes Gutenberg University Mainz, Germany. E-mail:hfrey@uni-mainz.de

${ }^{b}$ Texas A\&M University, College Station, USA.

E-mail: emilypentzer@tamu.edu
}

"seismograph" for current topics and emerging future trends.

This is particularly interesting because in the last decade numerous new challenges have come into focus in the polymer sciences, which are increasingly shaping our field, as are also reflected in this collection. Undoubtedly, increasing awareness of limited fossil resources and the plastic waste issue play an increasing role for polymer scientists.

The large number of excellent articles compiled in this collection shine light on the vast field of polymer science and span from catalytic polymer synthesis to controlled radical polymerization to optoelectronic materials and so on. Here, we highlight a handful of topics in this collection that represent current and future directions:

- Bio-based monomers and components. Starting compounds based on biorenewable sources are of increasing significance. This is expressed by the minireviews of $\mathrm{Li}$ and Tao on biorenewable cyclic lysine (DOI: 10.1039/D0PY01387K), as well as Della Monica and Kleij on terpene monomers (DOI: 10.1039/ D0PY00817F). As this field evolves, the connection between bio-based and "sustainable" materials must be delineated.

- Gradient and sequence-defined polymers. Techniques that enable the study and increasing precision control of copolymers can be exploited to generate perfectly sequence-defined structures. This is reflected in the work by Zhu et al. with palindromic sequence-defined polymers (DOI: 10.1039/D0PY01088J), and
Colombani et al.'s study on copolymer composition profiles and their ionization to weak polyelectrolytes (DOI: 10.1039/D0PY01059F). In addition, perfectly monodisperse block copolymers are studied by Petkau-Milroy, Palmans et al. with respect to their self-assembly in water (DOI: 10.1039/D0PY01161D).

"Smart", responsive polymers. Responsive polymers continue to play an important role in controlling materials properties. In this context Klinger et al. describe thermo- and oxidation-sensitive polymethacrylates based on sulfoxide groups (DOI: 10.1039/D0PY01321H).

- Polymer-based nanoparticles. Selfassembly of polymers into "unusual" structures are the focus of several articles. D'Agosto, Lansalot et al. report on a surfactant-free emulsion polymerization (DOI: 10.1039/D0PY01266A). 2D-lenticular aggregates are prepared by solution self-assembly of PNIPAM-based amphiphilic block copolymers, as presented by Semsarilar and coworkers (DOI: 10.1039/ D0PY01193B). Quintieri and Gröschel take a look at "naked micelles" as welldefined polymer nanoparticles (DOI: 10.1039/D0PY01408G). Further, anisotropic polymer nanoplatelets and the effect of chain defects on such structures are studied by Wurm and coworkers (DOI: $\quad 10.1039 / \mathrm{D} 0 \mathrm{PY} 01352 \mathrm{H}$ ), and Paulusse and coworkers propose reactive single-chain polymer nanoparticles as a versatile platform towards protein mimicry (DOI: 10.1039/D0PY00922A). Conjugated polymer-based nano-objects are reviewed by Choi et al. (DOI: 10.1039/ D0PY01389G). 
- Covalent bond exchange, adaptable networks and self-healing. Smulders and coauthors turn to molecular exchange dynamics in polyimine networks (DOI: 10.1039/D0PY01555E), and Shipp et al. demonstrate dynamic covalent exchange of anhydride moieties in poly(thioether anhydrides) (DOI: 10.1039/D0PY01267J).

- Polymer-systems for medical purposes. Polymers play an increasingly important role in the interface between synthetic and natural materials. Nguyen and Lai review the use of stimuli-responsive polymers for ocular disease treatment (DOI: 10.1039/D0PY00919A), and Tian and coauthors report the use of hyperbranched polymers for synergistic cancer chemotherapy (DOI: 10.1039/ D0PY00862A).

We hope our readers appreciate the excellent contributions from mid-career researchers from across the world that are compiled in this collection. The inspiration from reading these articles may not only come from the results reported, but also from the researchers' perseverance and dedication to moving the field of polymer chemistry forward during a period of great uncertainty. We hope you enjoy reading the many excellent contributions in this collection!

Reviews:

- Poly( $\varepsilon$-lysine) and its derivatives via ring-opening polymerization of biorenewable cyclic lysine

- Advancing the stimuli response of polymer-based drug delivery systems for ocular disease treatment

- Bioinspired structural color nanocomposites with healable capability

- Recent development in halogenbonding-catalyzed living radical polymerization

- From terpenes to sustainable and functional polymers

- Recent advances in the development and applications of nonconventional luminescent polymers

- A comprehensive review of the structures and properties of ionic polymeric materials

Perspectives:

- Direct formation of nano-objects via in situ self-assembly of conjugated polymers
- Pairing Suzuki-Miyaura cross-coupling and catalyst transfer polymerization

Communications:

- A shish-kebab-like supramolecular polymer and its light-responsive selfassembly into nanofibers

- Confined supramolecular polymers in water with exceptional stability, photoluminescence and chiroptical properties

- Mechanism and application of surface-initiated ATRP in the presence of a $\mathrm{Zn}^{0}$ plate

- Substituent effects in iniferter photopolymerization: can bond homolysis be enhanced by electronics?

- Catalyst free removal of trithiocarbonate RAFT CTAs from poly(vinylpyridine)s using tris(trimethylsilyl)silane and light

- Easily readable palindromic sequence-defined polymers built by cascade thiol-maleimide Michael couplings

- Cationic amphiphilic alternating copolymers with tunable morphology

- Crosslinked metallo-polyelectrolytes with enhanced flexibility and dimensional stability for anion-exchange membranes

Articles:

- Naked micelles: well-defined polymer nanoparticles from photo-cleavable block copolymer micelles

- Organocatalytic ring-opening polymerization of thionolactones: anything $\mathrm{O}$ can do, $\mathrm{S}$ can do better

- Preparation of well-defined 2D-lenticular aggregates by self-assembly of PNIPAM- $b$-PVDF amphiphilic diblock copolymers in solution

- Amphiphilic random and random block terpolymers with PEG, octadecyl, and oleyl pendants for controlled crystallization and microphase separation

- Hierarchical self-assembly of miktoarm star copolymers with pathway complexity

- The effect of polarity on the molecular exchange dynamics in imine-based covalent adaptable networks

- Advanced

spectroscopy, microscopy, diffraction and thermal analysis of polyamide adhesives and prediction of their functional properties with solid-state NMR spectroscopy
- A pyridinium-pended conjugated polyelectrolyte for efficient photocatalytic hydrogen evolution and organic solar cells

- Solution size variation of linear and dendritic bis-MPA analogs using DOSY- ${ }^{1} \mathrm{H}$ NMR

- Stereoselective polymerization of rac-lactide catalyzed by zwitterionic calcium complexes

- Effect of backbone and end-group regioisomerism on thermomechanical properties of vanillin-based polyurethane networks

- Clarification of the effects of topological isomers on the mechanical strength of comb polyurethane

- Controlled ring-opening polymerization of $N$-(3-tert-butoxy-3-oxopropyl) glycine derived $N$-carboxyanhydrides towards well-defined peptoid-based polyacids

- An AIE-driven fluorescent polysaccharide polymersome as an enzymeresponsive FRET nanoprobe to study the real-time delivery aspects in live cells

- Expanding the thiol-X toolbox: photoinitiation and materials application of the acid-catalyzed thiol-ene (ACT) reaction

- Organocatalyzed closed-loop chemical recycling of thermo-compressed films of poly(ethylene furanoate)

- Temperature-mediated molecular ladder self-assembly employing DielsAlder cycloaddition

- Thermo- and oxidation-sensitive poly(meth)acrylates based on alkyl sulfoxides: dual-responsive homopolymers from one functional group

- Guaiazulene revisited: a new material for green-processed optoelectronics

- Gradient and asymmetric copolymers: the role of the copolymer composition profile in the ionization of weak polyelectrolytes

- Dynamic covalent exchange in poly (thioether anhydrides)

- Investigations into CTA-differentiation-involving polymerization of fluorous monomers: exploitation of experimental variances in fine-tuning of molecular weights

- Poly(vinyl acetate-co-ethylene) particles prepared by surfactant-free emul- 
sion polymerization in the presence of a hydrophilic RAFT/MADIX macromolecular chain transfer agent

- Defect engineering of polyethylenelike polyphosphoesters: solid-state NMR characterization and surface chemistry of anisotropic polymer nanoplatelets

- Core hyper-cross-linked star polymers from block polymer micelle precursors

- Effects of crystallinity and dispersity on the self-assembly behavior of block co-oligomers in water

- DFT-calculation-assisted prediction of the copolymerization between cyclic ketene acetals and traditional vinyl monomers

- Exploring the difference of bonding strength between silver(I) and chalcogenides in block copolymer systems

- Semifluorinated, kinked polyarylenes via direct arylation polycondensation

- Insight into the synthesis of $N$-methylated polypeptides

- Time-dependent covalent network formation in extrudable hydrogels

- Functional polyimides based on diamine containing diarylethylene moieties and their photochromic mechanism studies

- Pentafluorophenyl-based singlechain polymer nanoparticles as a versatile platform towards protein mimicry

- Catechol-functionalized sequencedefined glycomacromolecules as covalent inhibitors of bacterial adhesion

- Identifying competitive tin- or metal-free catalyst combinations to tailor polyurethane prepolymer and network properties

- A dual drug-based hyperbranched polymer with methotrexate and chlorambucil moieties for synergistic cancer chemotherapy

- Kinetics and mechanisms of polycondensation reactions between aryl halides and bisphenol $\mathrm{A}$

- Impacts of performing electrolysis during organocatalyzed atom transfer radical polymerization

- Sequential and alternating RAFT single unit monomer insertion: model trimers as the guide for discrete oligomer synthesis

- Optimization of ring-opening metathesis polymerization (ROMP) under physiologically relevant conditions
Holger Frey, Polymer Chemistry Associate Editor

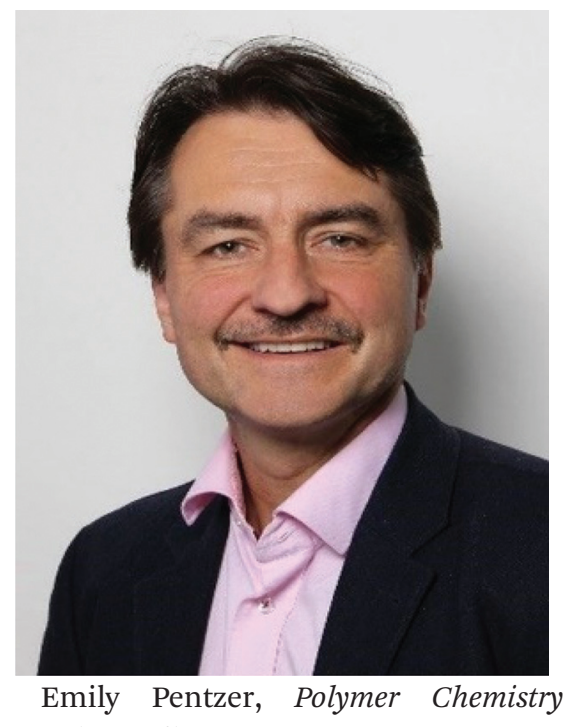

Associate Editor
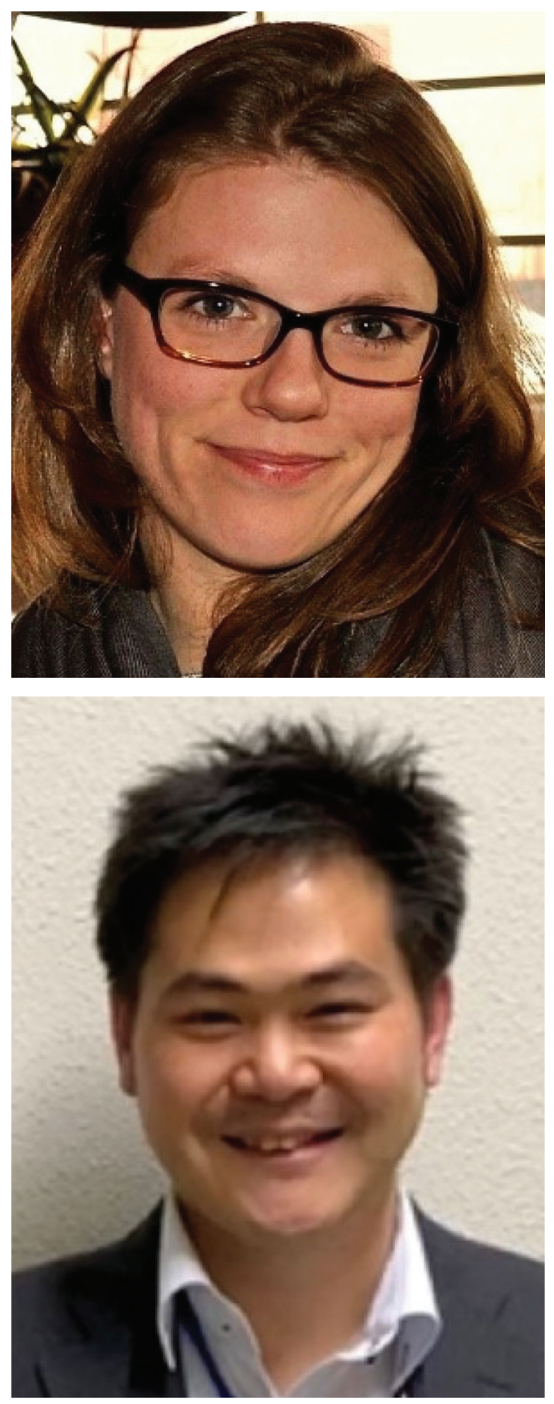

\section{Hiroharu Ajiro}

Hiroharu Ajiro received his $\mathrm{PhD}$ degree in 2004 from Nagoya
University under the direction of Prof. Yoshio Okamoto. In 2004-2005, he was a Postdoctoral Associate under the direction of Prof. Geoffrey W. Coates at Cornell University. $\mathrm{He}$ joined the Center for Advanced Medical Engineering and Informatics at Osaka University as a Specially Appointed Lecturer in 2006, and was promoted to a Specially Appointed Associate Professor in 2011, under the direction of Prof. Mitsuru Akashi. He moved to Nara Institute of Science and Technology in 2015 as an Associate Professor to start his laboratory as a PI, and he was promoted to Professor in 2019. His interest lies in the creation of novel functional polymers, based on monomer synthesis, structural control of polymers and polymer-polymer interactions.

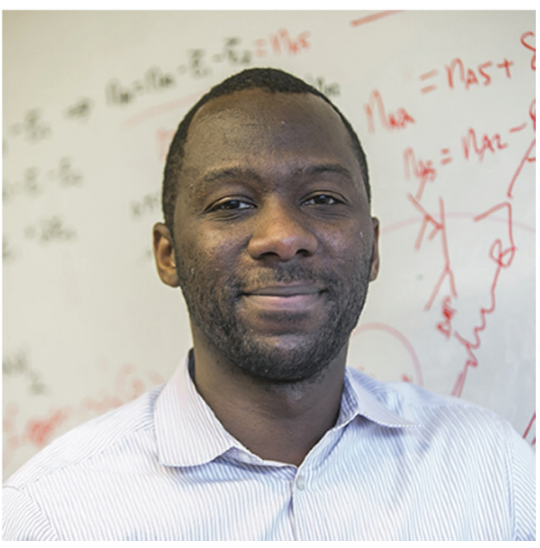

\section{Christopher Alabi}

Christopher Alabi received his B.S. in Chemistry and B.E. in Chemical Engineering from New York University and Stevens Institute of Technology in 2004. He obtained a graduate degree at Caltech with Dr Mark Davis and was an NIH Postdoctoral Fellow with Dr Langer and Dr Anderson from 2009 to 2013. Chris Alabi joined Cornell CBE in 2013 and was promoted to Associate Professor with Indefinite Tenure in 2019. Research in the Alabi lab seeks to understand how the sequence and structure of a macromolecule affect its properties with an eye towards engineering sustainable materials and biomolecular therapeutics. 


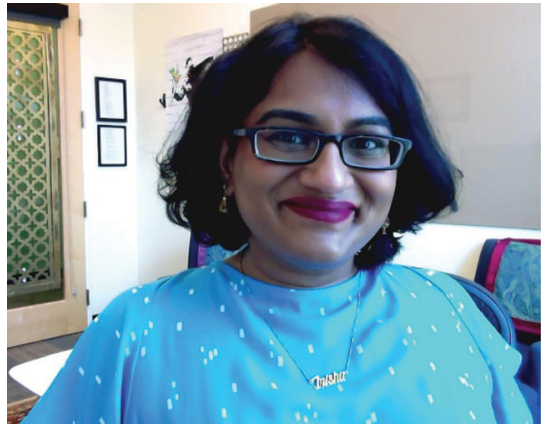

Trisha L. Andrew

Trisha L. Andrew is a Professor of Chemistry and Chemical Engineering at the University of Massachusetts Amherst. She directs the Wearable Electronics Lab, a multi-disciplinary research team that produces garment-integrated technologies using chemical vapor deposition, a process that effects polymerization and deposition of molecular semiconductors from the vapor phase onto any desired surface. Trisha started her career as an Assistant Professor of Chemistry and Electrical Engineering at the University of Wisconsin-Madison, after receiving her Ph.D. from MIT in 2011. She is a David and Lucile Packard Foundation Fellow, a National Academy of Sciences Kavli Fellow, an Air Force Young Investigator, an ARPA-E Investigator, and a L'Oréal USA For Women in Science Fellow, and was named as one of Forbes magazine's “30 Under 30" innovators in energy.

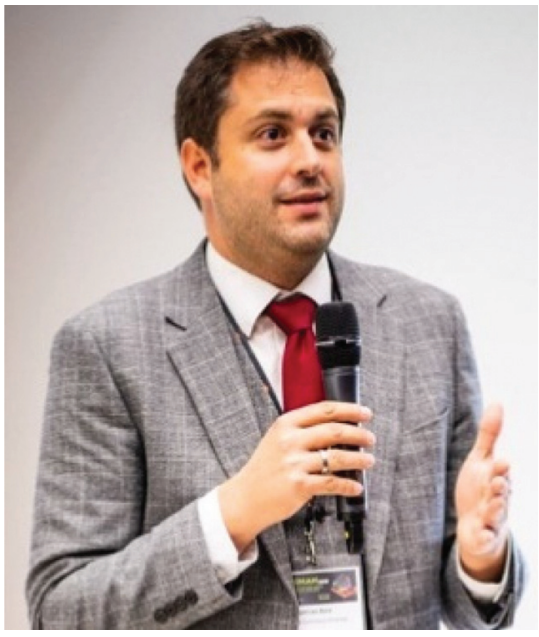

\section{Matthias Barz}

Dr Matthias Barz studied chemistry at the Johannes Gutenberg-University (JGU) Mainz (Germany) and the Seoul National University (South Korea), and received a diploma degree in chemistry in 2006 and a PhD in polymer chemistry in 2009 (Prof. R. Zentel). Afterwards, he worked in the laboratories of Maria J. Vicent at the CIPF and T. Kirchhausen at Boston Children's Hospital, Harvard Medical School. In 2013, he became an independent junior research group leader at the JGU and established polypept(o)ides as functional biomaterials. Since 2020, he has been a full professor in biotherapeutic delivery at the LACDR, Leiden University. Matthias Barz has published more than 100 research papers, commentaries, reviews, book chapters and patents. For his independent research he has received numerous awards, including the prestigious Dozentenpreis (FCI) and the Hermann Schnell Scholarship (GDCH), and he was named an ACS PMSE Young Investigator in 2018.

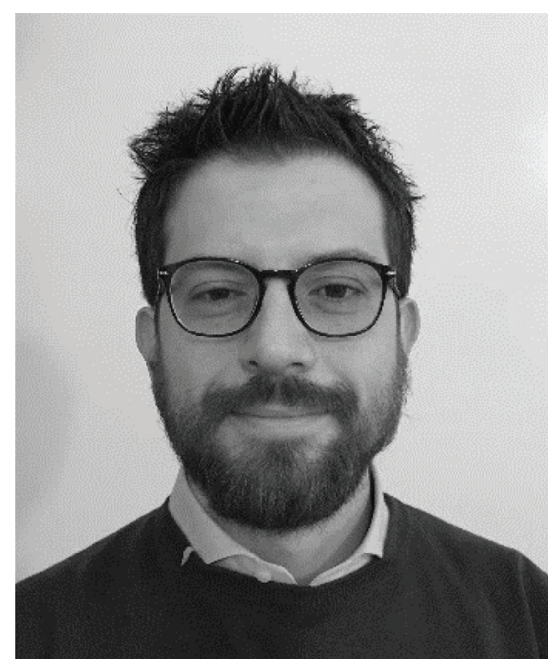

\section{Edmondo M. Benetti}

Dr Edmondo M. Benetti graduated in chemistry from the University of Padova (Italy), and carried out his $\mathrm{PhD}$ at the University of Twente (The Netherlands), working in the Department of Materials Science and Technology of Polymers (2009). He joined the Department of Materials at ETH in 2009 as a PostDoc (ETH fellow) working in the groups of Prof. Nicholas D. Spencer and Prof. Marcus Textor. Since 2014 he has been a senior scientist and group leader, coordinating the activities of the Polymer Surfaces Group, which is now active between the Department of Materials at ETH Zürich and the Swiss Federal Laboratories for Materials Science and
Technology (Empa). His research interests focus on controlled polymerizations applied to interfaces, and the fabrication and physicochemical characterization of synthetic biointerfaces.

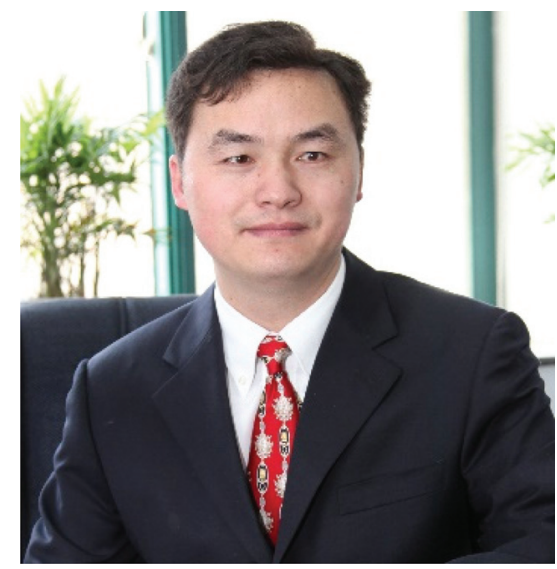

\section{Weifeng Bu}

Weifeng Bu received his B.S. and $\mathrm{Ph}$. D. degrees from Jilin University in 1999 and 2004, respectively. In 2005, he went to The University of Hong Kong as a research assistant. Then he worked at National Institute for Materials Science (NIMS) in Japan (2006 and 2007) as a postdoctoral fellow and at The University of Tokyo as a Japan Society for the Promotion of Science (JSPS) fellow (2008 and 2009). In 2009, he joined the School of Chemistry and Chemical Engineering at Lanzhou University as a full professor. His scientific interests include the selfassembly and functions of polymer-inorganic composites.

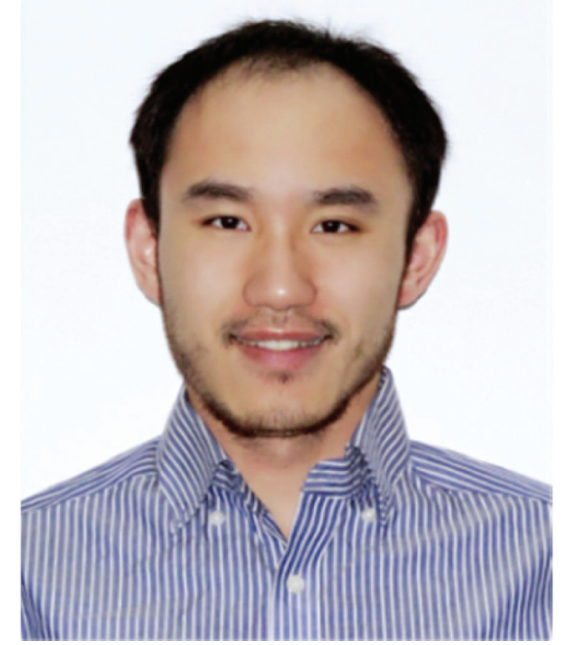

\section{Mao Chen}

Mao Chen obtained his B.S. and Ph.D. at Wuhan University (2006, 
2011) under the direction of Prof. Aiwen Lei and Prof. Xumu Zhang. From 2012, Mao worked as a Postdoc at MIT with Prof. Stephen L. Buchwald and Prof. Jeremiah A. Johnson, successively, and was promoted to research scientist in 2016. Subsequently, Mao started his independent research in the Department of Macromolecular Science, State Key Laboratory of Molecular Engineering of Polymers at Fudan University. He has received an Overseas Talent Program of China Award, a Thieme Chemistry Journals Award, and a Dow Innovation Challenge Award. His primary research interests include development of creative polymerization methods and cutting-edge technologies toward controlled synthesis of polymers, and engineering of highperformance polymers to solve challenges at the interface of energy, the environment and intelligent manufacturing.

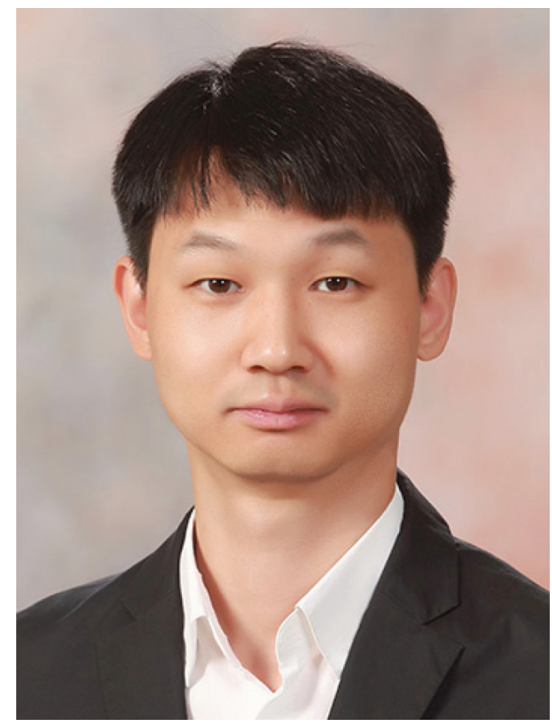

\section{Tae-Lim Choi}

Tae-Lim Choi was born in Seoul in 1977. He obtained his BS from KAIST in 1999, and his PhD from Caltech under the supervision of Bob Grubbs, in 2003. Then he moved to UC Berkeley as a post-doc researcher under the guidance of Jean Frèchet until 2004. He came back to S. Korea and worked at Cheil Industries, Samsung, for four years. In 2008, he started his independent career as an assistant professor in the Department of Chemistry, Seoul National University. He was promoted to full professor in 2017. His research interest is mainly in synthesis, focusing on developing new methods (living, cascade or diversity-oriented polymerizations etc.) to synthesize various macromolecules and understanding their mechanisms. Recently, his focus has moved to applying these synthetic tools in the self-assembly of conjugated polymers to prepare various semiconducting nanostructures. Since 2013, he has served as an editor of Journal of Polymer Science. He is a member of the Young Korean Academy of Science and Technology.

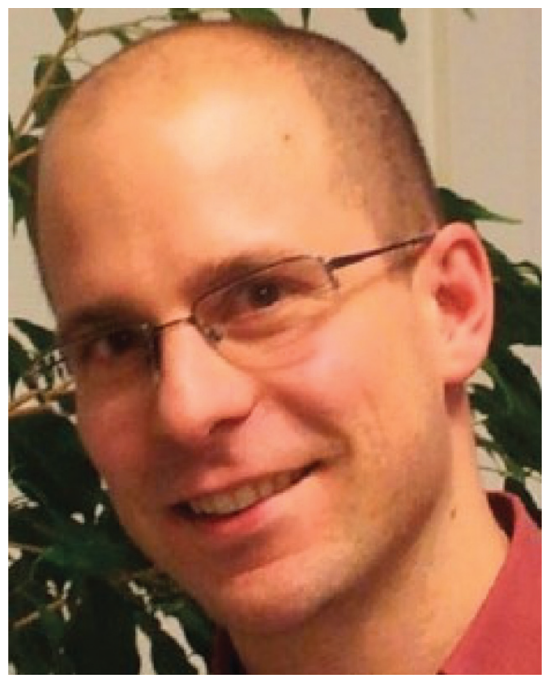

\section{Olivier Colombani}

Olivier Colombani received a $\mathrm{PhD}$ in polymer chemistry from Université Pierre et Marie Curie (France) in 2003. He worked as a post-doctoral fellow at Universität Bayreuth (Germany, 2004-2005) and at the Centre of Nuclear Energy (CEA, France, 2005-2006). In 2006, he was appointed assistant pro- fessor at Le Mans Université (France). His research interests focus on the synthesis and self-assembly of polymers in solution. In this field, he aims to control the exchange dynamics and morphology of supramolecular structures at the nanoscale via a fine control of the chemical structure of the polymers at the molecular scale.

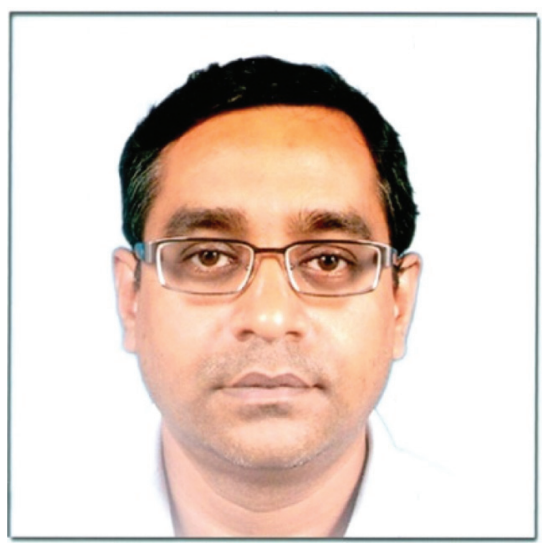

Priyadarsi De

Dr Priyadarsi De is a Professor in the Department of Chemical Sciences at Indian Institute of Science Education and Research Kolkata (IISER Kolkata), India. He received his Ph.D. degree from Indian Institute of Science, India. After his post-doctoral studies at UMASS Lowell (2002-2006) and Southern Methodist University (2007-2008), he worked at PhaseRx Inc. Seattle for fifteen months before joining IISER Kolkata in November 2009. His research group at IISER Kolkata mostly works on controlled synthesis of bio-inspired macromolecular architectures from naturally occurring amino acids and fatty acid based renewable resources for various applications. Currently, he is an Advisory Board member of Polymer Chemistry (Royal Society of Chemistry, September 2015-present) and an Associate Editor of Journal of Macromolecular Science, Part A: Pure and Applied Chemistry (Taylor \& Francis Group, April 2019present). 


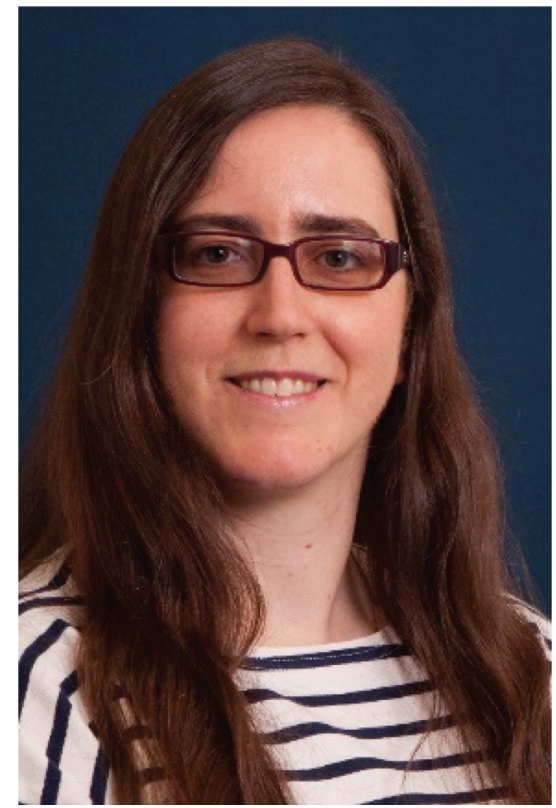

Marianne 'Marion' Gaborieau

Marion Gaborieau is a polymer scientist and spectroscopist. Her PhD work, funded by industry at the Max Planck Institute for Polymer Research (MPIP, Mainz, Germany), was devoted to the characterisation of the structure and dynamics of polyacrylics for paints and adhesives by solid-state NMR spectroscopy. She currently holds a senior research lectureship in the School of Science at Western Sydney University, Australia. Her research is devoted to the characterisation of complex industrial polymeric materials, especially in the solid state. Her projects include adhesives, membranes for water purification, agromaterials such as starch and cellulose for bioplastics or paper coatings, as well as foods. Characterisation methods include solid-state NMR spectroscopy to shed light on the functional properties of materials.

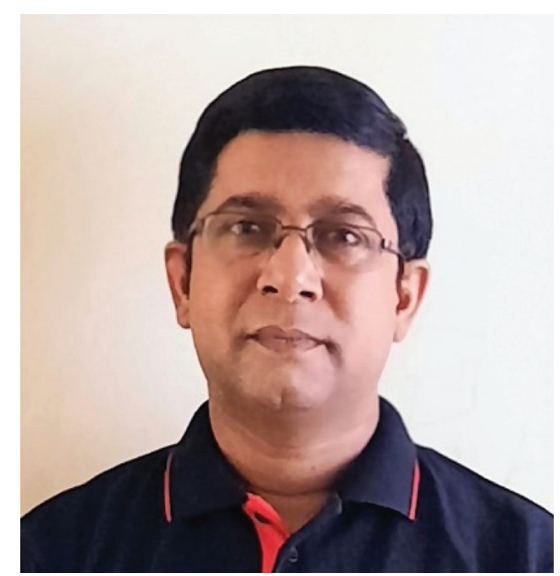

Suhrit Ghosh
Suhrit Ghosh was born in India in 1976. He did a PhD with Professor S. Ramakrishnan at IISc Bangalore, India, during 2000-2005. Subsequently, he worked as a postdoctoral Research Associate with Professor S. Thayumanavan at the University of Massachusetts, Amherst, USA. He then worked as a Humboldt Postdoctoral Fellow with Professor F. Würthner at the University of Würzburg, Germany. In 2008, he returned to India and was appointed as an Assistant Professor at IACS, Kolkata, where he is currently a Senior Professor in the School of Applied and Interdisciplinary Sciences. His research interests include structure and function in the supramolecular assembly of $\pi$-systems and macromolecules. $\mathrm{He}$ currently serves as an Associate Editor of $R S C$ Advances and an Editorial Advisory Board member of Macromolecules.

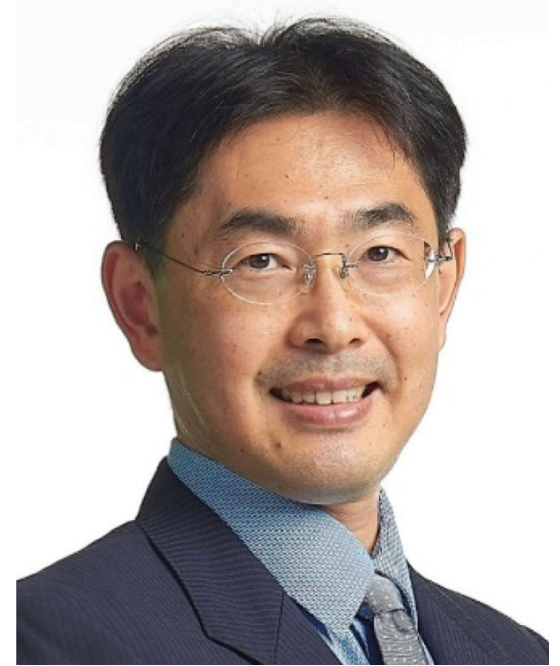

\section{Atsushi Goto}

Atsushi Goto is a professor and a Provost's Chair professor at Nanyang Technological University (NTU), Singapore. He received his PhD (2001) from Kyoto University, Japan, and was appointed as an instructor (2001), an assistant professor (2002), and an associate professor (2010) at Kyoto University. He moved to NTU and was appointed as an associate professor (2015) and a professor (2020). His research interests are polymer chemistry and polymer materials, particularly relating to controlled synthesis of polymers. He has published $>\mathbf{1 1 0}$ peer-reviewed papers in inter- national journals with $>7200$ citations (h-index of 41) and filed $>50$ patents. $\mathrm{He}$ has received a Shimadzu-SNIC Industry Award (2020), a Singapore NRF Investigatorship Award 2018 (2018), a Photopolymer Science and Technology Best Paper Award (2018), and so on. He is an Advisory Board member for Polymer Chemistry.

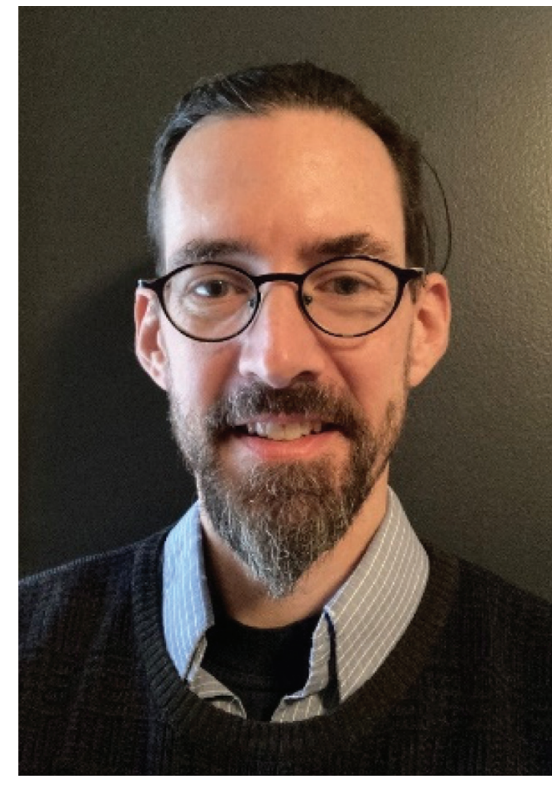

Scott M. Grayson

Scott M. Grayson is the Joseph H. Boyer Professor of Chemistry at Tulane University. He has completed a number of projects related to polymer applications, including a new "click" chemistry route to prepare cyclic polymers and a new calibration standard for mass spectrometry with bis-MPA dendrimers. He is currently working on a linear bis-MPA polymer that is virtually identical to bis-MPA dendrimers, though with a purely linear architecture.

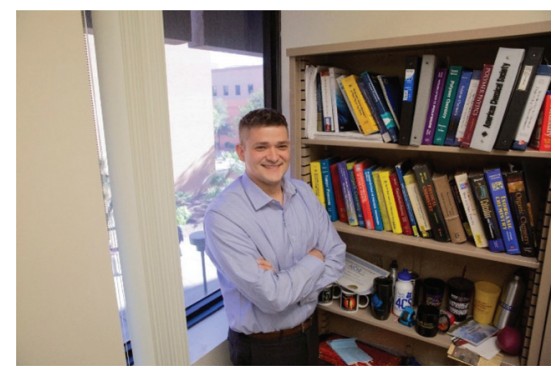

\section{Matthew Green}

Prof. Matthew Green joined the faculty at Arizona State University in 
Chemical Engineering in 2014 after completing a Ph.D. in Chemical Engineering in 2011 at Virginia Tech with Prof. Timothy Long and a postdoc at the University of Delaware in the Chemical and Biomolecular Engineering Department with Prof. Thomas Epps, III and Prof. Millicent Sullivan. His training as a synthetic polymer chemist and chemical engineer positions his research group at the critical intersection of the disciplines of health, the environment, and advanced materials. His laboratory is integrating macromolecular design with controlled synthesis techniques to produce hierarchical and multifunctional materials with particular interest in the interplay between electrostatic interactions and microstructure, inter-phase interactions, thermomechanical properties, and transport. These features can be used to tune the material properties for applications ranging from membranes for water purification or $\mathrm{CO}_{2}$ capture to polymeric nanocomposites.

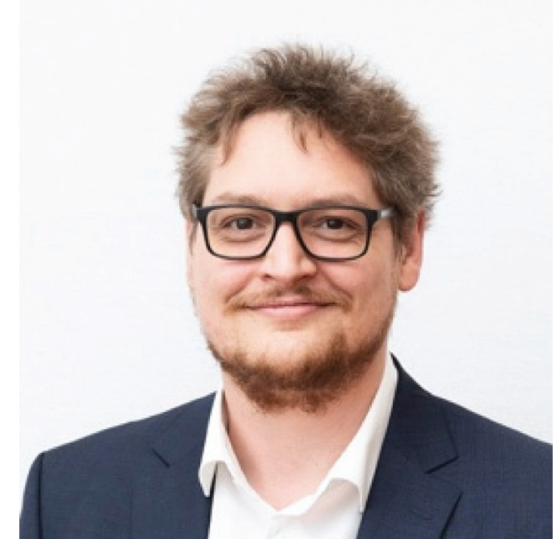

André Gröschel

André Gröschel studied chemistry at the University of Bayreuth and graduated in 2012, working on hierarchical self-assembly of block copolymers. From 2013 to 2015, he joined the Department of Applied Physics at Aalto University in Helsinki, pursuing his postdoc on biomimetic nanocomposites and photonic materials. In
2016, he received an endowed junior professorship in Physical Chemistry at the University of Duisburg-Essen, and in 2017, he started an Emmy Noether research group. In 2020, he was appointed as a Professor in the Institute of Physical Chemistry at the University of Münster, where his group is currently located at the Center for Soft Nanoscience (SoN). He has published over 60 papers, several reviews and three book chapters. His research interests comprise selfassembly of block copolymers, electron tomography, multicompartment materials and Janus and topographic nanoparticles.

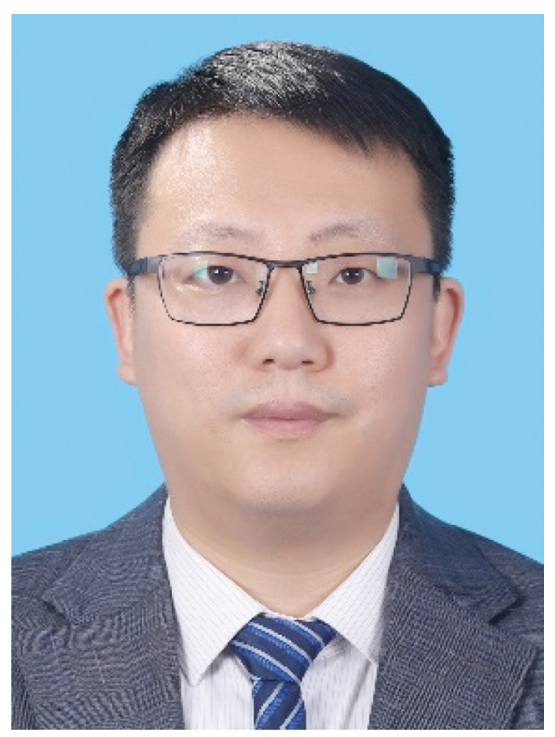

\section{Fei Huang}

Fei Huang received his BS degree in Chemistry from Peking University in 2000 and gained his $\mathrm{PhD}$ degree in Materials Science from South China University of Technology in 2005 under the supervision of Prof. Yong Cao. After postdoctoral work at University of Washington with Prof. Alex K.-Y. Jen, he began his academic career in 2009 as a full professor at South China University of Technology, and he is now the associate director of the State Key Laboratory of Luminescent Materials and Devices. His main interests are in the fields of organic functional materials and devices for optoelectronics.

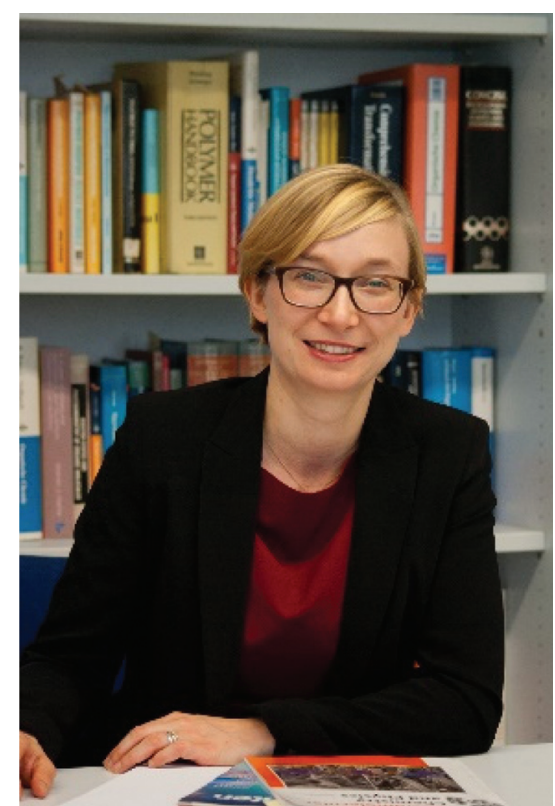

\section{Laura Hartmann}

Laura Hartmann finished her $\mathrm{PhD}$ under the supervision of Hans Börner and Markus Antonietti at the Max Planck Institute of Colloids and Interfaces in 2007. Thereafter, she worked as a Research Fellow at Stanford University. In 2009 she started her independent Emmy Noether research group within the Department for Biomolecular Systems headed by Peter Seeberger. Since July 2014 she holds the chair for Macromolecular Chemistry at the Heinrich-Heine-University Düsseldorf. Her research is focused on combining solid phase and polymer synthesis to obtain monodisperse, sequence-defined polymers. In particular, she is interested in glycopolymers and glycomaterials for use in biotechnology and biomedicine.

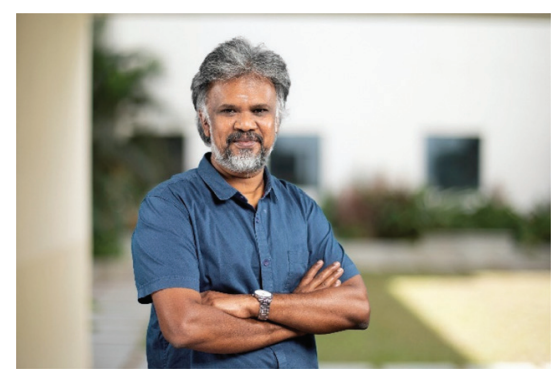

\section{Manickam Jayakannan}

Manickam Jayakannan is a professor at the Department of Chemistry, Indian Institute of Science Education and 
Research, Pune (IISER-Pune). He received his Bachelors and Masters degrees in chemistry from Madurai Kamaraj University and his Ph.D. from Indian Institute of Science (Professor S. Ramakrishnan's group), India. After completing his post-doctoral work at Eindhoven University of Technology, The Netherlands (Prof. Rene A. J. Janssen's group), he returned to India and had a short stint as a polymer scientist at JFWTC-GE Global Research in Bangalore. He began his career as a scientist at CSIR-NIIST Trivandrum and then he moved to IISER-Pune to embark on the journey of establishing the new academic institute. Currently he is continuing as a professor in the same institute and he has published close to 100 papers. His group has contributed to the development of L-amino acid based functional polymers, PCL block copolymers and polysaccharide nano-carriers as therapeutics for cancer and in the treatment of infectious diseases.

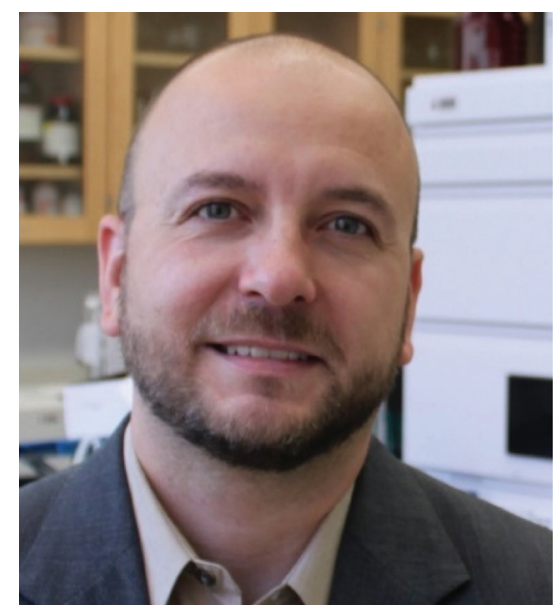

\section{Justin Kennemur}

Justin G. Kennemur grew up in Virginia and earned a B.S. degree in chemistry at Radford University. After working for three years as an analytical polymer chemist at Polymer Solutions Incorporated in Blacksburg, VA, he attended graduate school at North Carolina State University and earned a Ph.D. in polymer chemistry under the guidance of Bruce M. Novak. After a postdoctoral appointment co-advised by Marc A. Hillmyer and Frank S. Bates at the University of Minnesota, he began his appointment as an Assistant Professor in the Department of Chemistry and Biochemistry at Florida State University in Fall of 2014 and was promoted to Associate Professor with tenure in Fall of 2020. His recognitions include the NSF CAREER Award, 2018 PMSE Young Investigator, 2018 Polymer Chemistry Emerging Investigator, and the 2017-18 FSU Undergraduate Teaching Award.

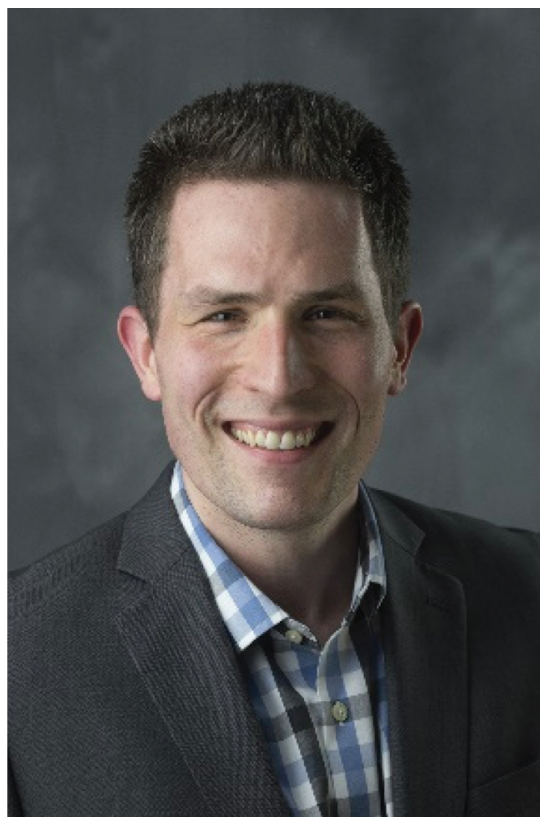

\section{Matt Kiesewetter}

Matt Kiesewetter was born in 1982 in Normal, IL. His initial training was in classic physical organic chemistry with Professor Cheryl D. Stevenson at Illinois State University (ISU). He received his B. $\mathrm{S}$. in chemistry, summa cum laude, from ISU in 2004. He conducted his graduate research in catalysis under the advisement of Professor Robert M. Waymouth and Dr James L. Hedrick (IBM) at Stanford University where he was a NSF Graduate Research Fellow. After a Ruth L. Kirschstein Postdoctoral Fellowship (NIH) with Prof. Tim Swager at MIT, he joined the faculty at the University of Rhode Island (URI) in 2013. Promoted in 2018, he is currently an Associate Professor of Chemistry. His current research interests are in homogeneous catalysis, supramolecular interactions, polymerization chemistry and pollinator conservation. His awards include a CAREER Award from the NSF (2016), an ACS Polymeric Materials Science and Engineering (PMSE) Young Investigator
Award (2017), and a Graduate Mentoring Award (2017) and Research Excellence Award (2016) from URI.

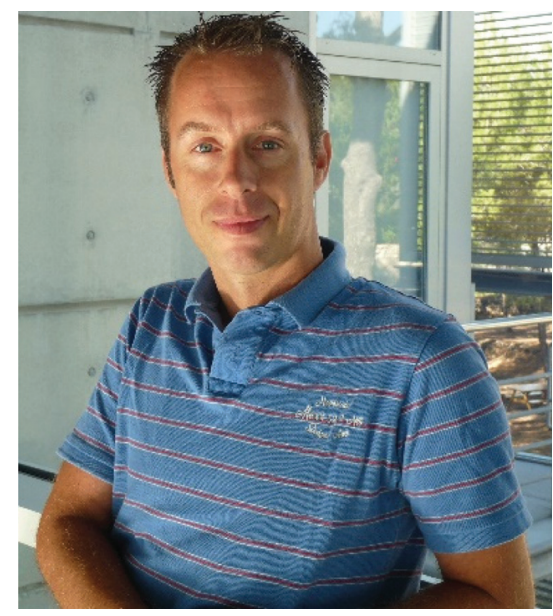

\section{Arjan Kleij}

Arjan W. Kleij has been an independent ICIQ group leader and ICREA fellow in Tarragona (Spain) since 2006 after finishing two postdoctoral (Madrid \& Amsterdam) and two industrial appointments (Avantium Technologies \& Hexion Specialty Chemicals). Among his main interests is the use of renewable feedstocks such as $\mathrm{CO}_{2}$ and terpenes in the creation of more complex and functional polymers through catalysis engineering, thereby creating new types of polyesters and polycarbonates with functional diversity for potential use in material development.

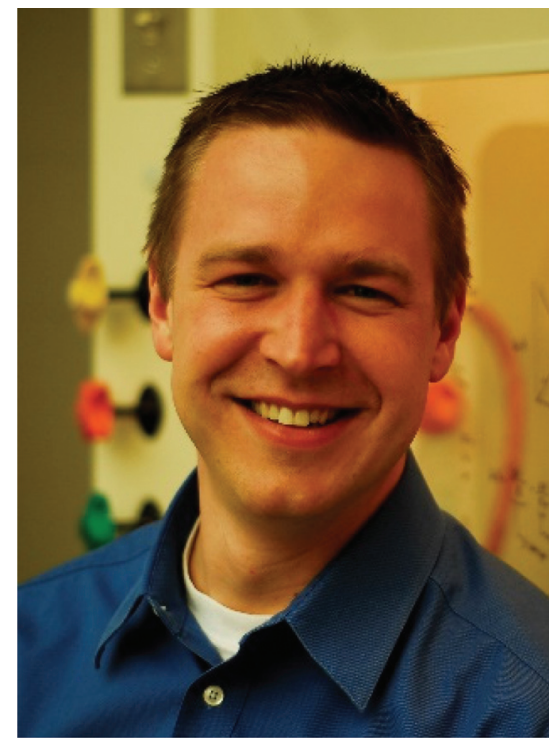

\section{Christopher Kloxin}

Chris Kloxin received a $\mathrm{PhD}$ in Chemical Engineering at North Carolina 
State University and did his post-doctoral work at the University of Colorado, Boulder under the guidance of Christopher Bowman. In 2014, he joined the faculty at the University of Delaware as an Assistant Professor in the Departments of Materials Science and Engineering and Chemical and Biomolecular Engineering, and he was promoted to Associate Professor in 2020. Major research efforts in his group are the synthesis and characterization of polymer networks and nature-inspired polymeric assemblies.

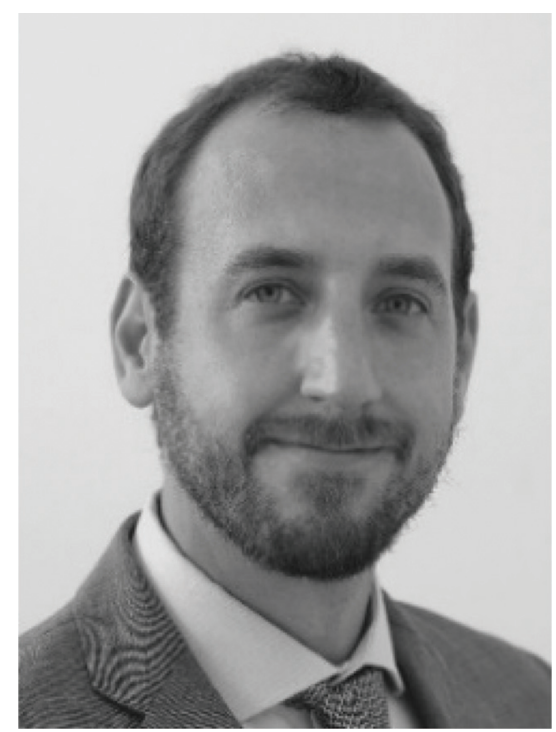

Daniel Klinger

Daniel Klinger is a Junior Professor at Freie Universität Berlin (FUB) where he is developing new synthetic strategies for functional polymer nanomaterials. Daniel obtained his $\mathrm{PhD}$ at the Max Planck Institute for Polymer Research under the guidance of Prof. K. Landfester and then joined the University of California as a postdoctoral researcher with Prof. C. J. Hawker. Here, he combined his existing experience in the fields of stimuliresponsive materials and colloidal chemistry with surfactant-directed block copolymer self-assembly in nanoparticles. Now, at FU Berlin, his most recent work focuses on stimuli-respon- sive polymers as new building blocks for functional nanomaterials, (amphiphilic) nanogels for drug delivery and catalytic applications, as well as controlling shape and morphology in phase-separated block copolymer nanoparticles.

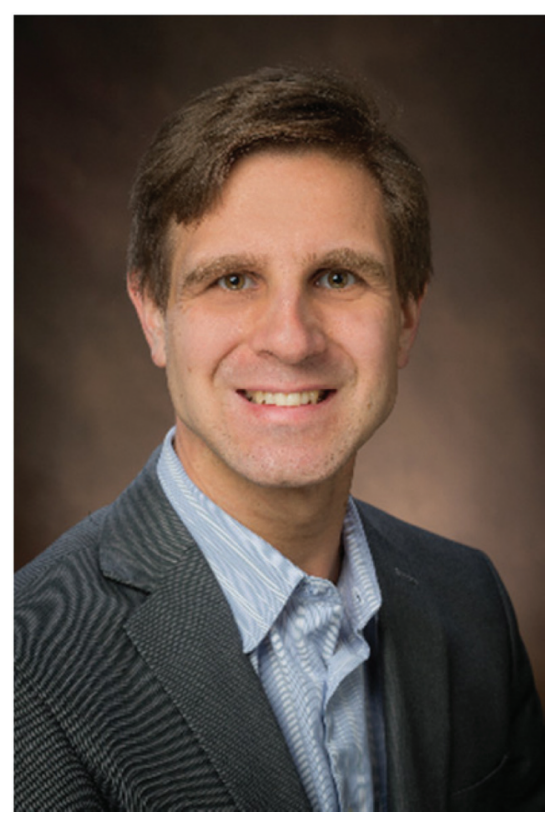

\section{Dominik Konkolewicz}

Dominik Konkolewicz earned his Ph.D. from the University of Sydney, advised by Prof. Sébastien Perrier, focusing on experimental and theoretical tools for highly branched polymers. Subsequently, he did postdoctoral work at Carnegie Mellon University from 2011 to 2014, advised by Prof. Krzysztof Matyjaszewski, where he studied synthetic and mechanistic aspects of ATRP. In August 2014, he joined Miami University in Oxford, $\mathrm{OH}$ as an Assistant Professor of Organic Chemistry. In 2019 he was promoted to Associate Professor. His research group consists of both graduate and undergraduate researchers working in the fields of organic chemistry, polymer chemistry, materials science and biohybrid materials. His team focuses on mechanism and funda- mental science driven discoveries in the fields of dynamic and responsive polymers, as well as biohybrid materials.

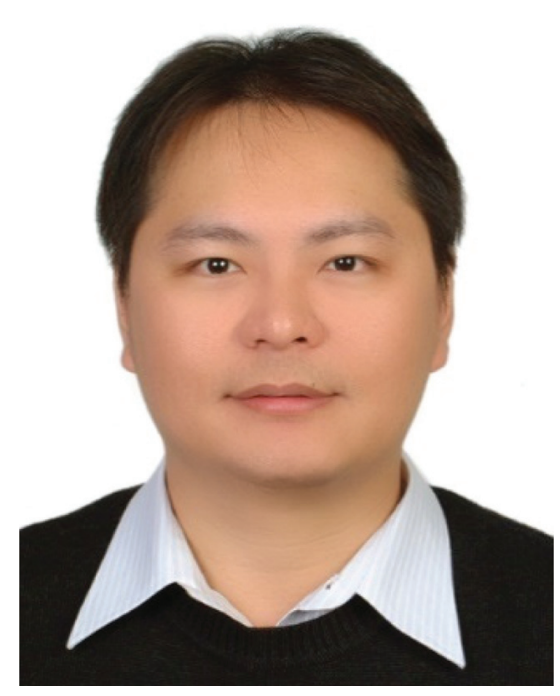

\section{Jui-Yang Lai}

Dr Jui-Yang Lai received his Ph.D. from the Department of Chemical Engineering, National Tsing Hua University, Taiwan. Since 2014, he has been a Full Professor at Chang Gung University, Taiwan. Dr Lai's primary research activities are centered on the design and development of functional biomaterials, either from natural or synthetic sources, for ophthalmic use, particularly in tissue engineering, drug delivery, and nanomedicine. His major research projects involve ocular biocompatibility assessment, corneal/ retinal cell construct fabrication, topical/intraocular pharmaceutical dosage formulation, and metallic/ carbon-based nanotherapeutics evaluation. Dr Lai has published more than 100 scientific papers (3000 citations, h-index = 32) and filed numerous patent applications. He actively participates in the peer review process for scientific publications (over 800 manuscripts) and also serves as a member of the Editorial Board for several scholarly journals. 


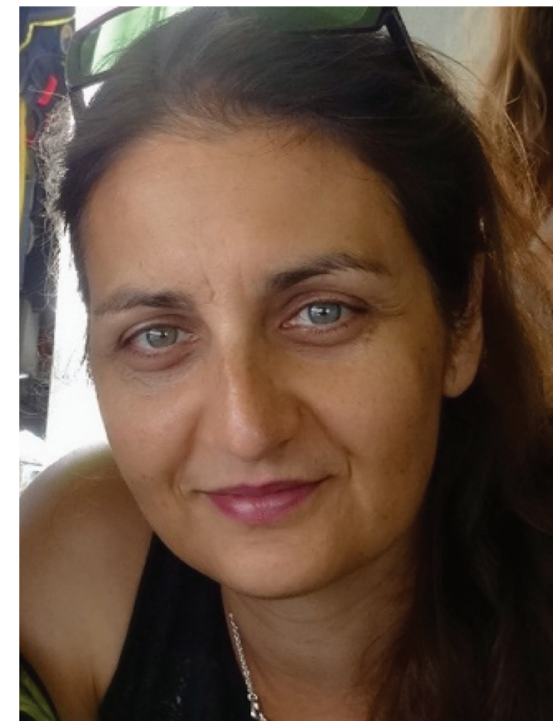

Muriel Lansalot

Muriel Lansalot obtained her PhD from the University Pierre and Marie Curie (Paris, France) in 1999. After postdoctoral fellowships at the Aix-Marseille University and at the University of New South Wales in Sydney, she moved to Lyon in 2003 to work in the joint unit between the CNRS and the bioMérieux company, first as a post-doctoral fellow and then as a CNRS researcher. In 2008, she joined the Chemistry, Catalysis, Polymers and Processes group (C2P2, Lyon), where her research interests focus on the synthesis of various kinds of polymer and organic/ inorganic colloids via free radical polymerization and RDRP techniques (including PISA). Her current studies also deal with photopolymerization in dispersed media, synthesis of degradable particles and selfhealing polymer films. Since 2018 she has served as an Advisory Board member for Polymer Chemistry.

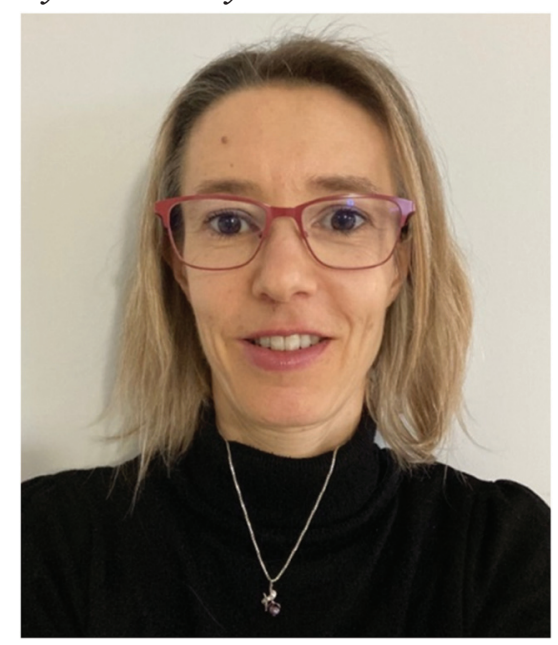

Catherine Lefay
Dr Catherine Lefay completed her PhD in polymer chemistry in 2006 under the supervision of Professor Bernadette Charleux at the University Pierre and Marie Curie (Paris, France). She then joined the group of Professor Christopher Barner-Kowollik (CAMD, University of New South Wales, Sydney, Australia) as a postdoctoral researcher. In 2007, she returned to France and started working as a lecturer at Aix-Marseille University (AMU, Marseilles, France). Her research currently focuses on the synthesis of (bio)degradable polymers, antimicrobial materials and controlled radical polymerization.

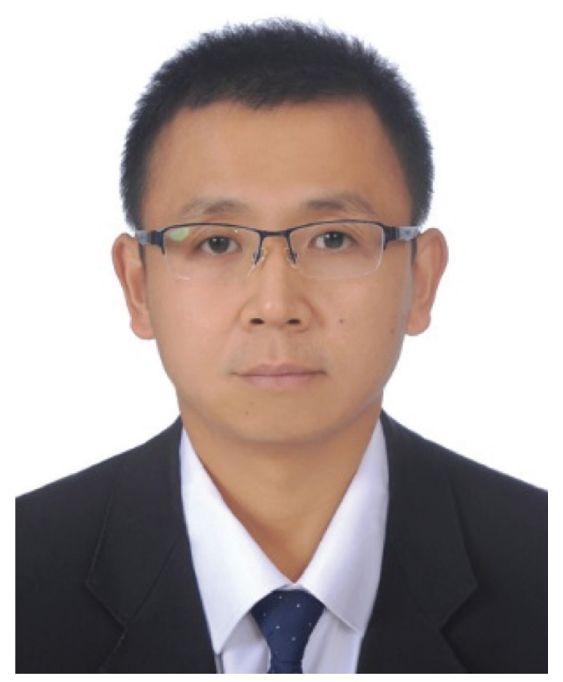

\section{Bo Liu}

Bo Liu received his Ph.D. degree from Changchun Institute of Applied Chemistry, Chinese Academy of Sciences under the supervision of Professor Dongmei Cui. His Ph.D. thesis was "Rare-earth metal complexes: synthesis and their catalytic activity". In 2010, he joined Prof. JeanFrançois Carpentier's group as a postdoctoral researcher supported by the European Frame Program-Marie Curie Fellowship, studying alkalineearth metal chemistry. In 2013, he went back to Changchun Institute of Applied Chemistry and was appointed as an associate professor. In December 2019, he was promoted to Professor. His current research interests focus on sequence controlled coordination polymerization. $\mathrm{He}$ has published more than 40 papers in J. Am. Chem. Soc., Angew. Chem., Int. Ed., Mater. Horiz., ACS Catalysis, Macromolecules, Chem. - Eur. J., etc., and has applied for 8 patents. In 2018, he was granted "the innovation award of rubber science and technology, China”.

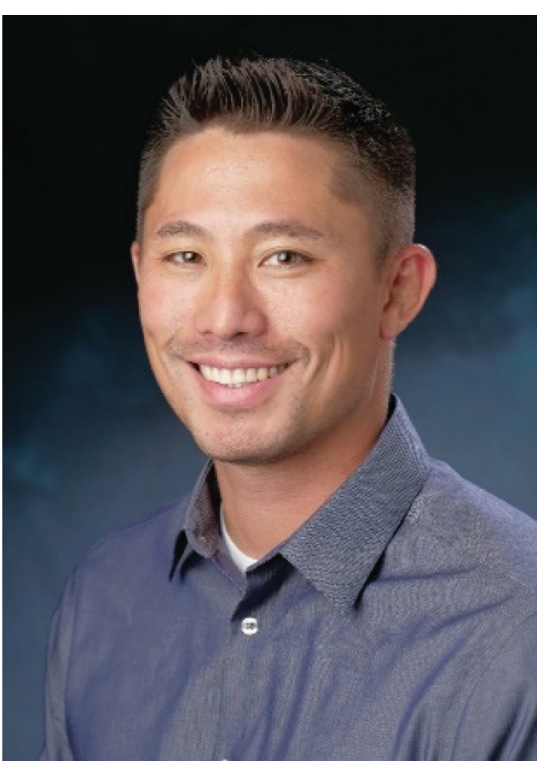

\section{Garret Miyake}

Garret Miyake grew up in Canby, Oregon and earned his B.S. at Pacific University. He performed his Ph.D. studies with Eugene Chen at Colorado State University before conducting postdoctoral research with Robert Grubbs at the California Institute of Technology. He is currently an Associate Professor of Chemistry at Colorado State University. The Miyake group has research interests in the fields of photoredox catalysis, organocatalyzed atom-transfer radical polymerization, and the synthesis of block copolymers that self-assemble into photonic crystals. He has been awarded the Sloan Research Fellowship, the Cottrell Scholar Award, the Camille Dreyfus TeacherScholar Award, and the American Chemical Society's Division of Polymer Chemistry Mark Young Scholar Award. 


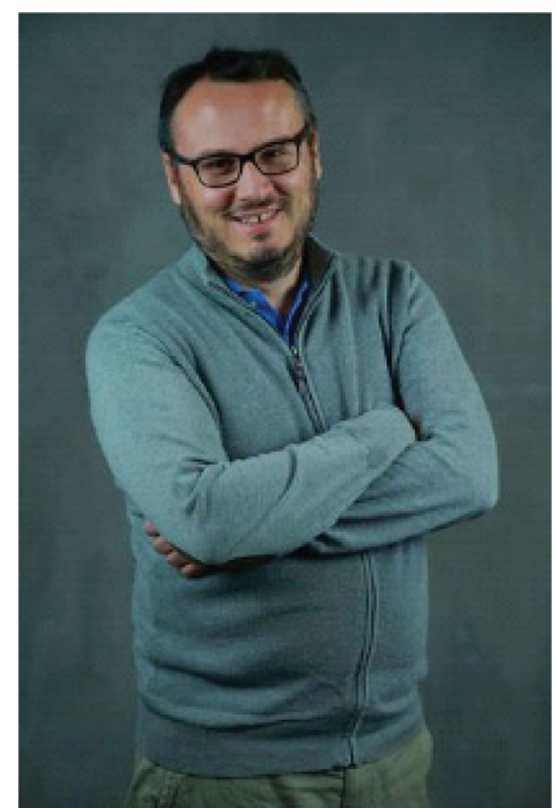

Vincent Monteil

Vincent Monteil obtained his Ph.D. from the University of Lyon in 2002 under the supervision of Roger Spitz and Christophe Boisson where he worked on catalytic copolymerization of ethylene and butadiene. He subsequently moved to the group of Stefan Mecking (University of Freiburg then Constance) as a postdoctoral researcher working on catalytic polymerizations in water. In 2005, he returned to Lyon as a CNRS Research Associate in the Laboratory of Chemistry, Catalysis, Polymers and Processes. He became CNRS Research Director in 2017. His research interests deal with the use of catalysis in polymer synthesis, the synthesis of polyolefins by catalytic and/or radical polymerization, and more recently with the chemical recycling of polymers (catalytic depolymerization).

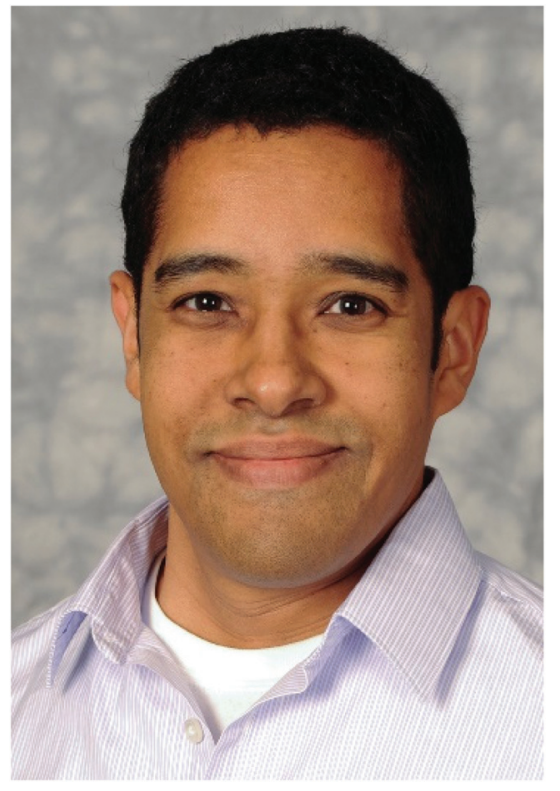

\section{Alshakim Nelson}

Alshakim Nelson is an Associate Professor in the Department of Chemistry at the University of Washington. He received his $\mathrm{PhD}$ in organic chemistry from UCLA in 2004 and then was a NIH postdoctoral fellow at the California Institute of Technology. Dr Nelson joined the IBM Almaden Research Center in 2005 as a Research Staff Member where he focused on the synthesis of nanomaterial building blocks that enabled large area nanomanufacturing via self-assembly. In 2015, Dr Nelson joined the faculty at the UW, where his research group focuses on the synthesis, characterization, and processing of stimuli-responsive polymers and biomaterials for $3 \mathrm{D}$ printing.

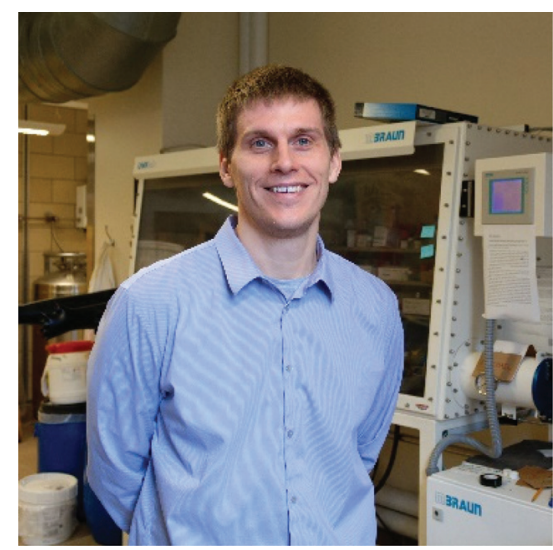

\section{Kevin Noonan}

Kevin Noonan is a Canadian-born chemist who completed his $\mathrm{PhD}$ and postdoc work at UBC and Cornell. He joined the Department of Chemistry at Carnegie Mellon in 2011 where he is currently an Associate Professor. His research interests are broadly centred around the design and synthesis of new molecules and polymers. He has been exploring different methods to prepare well-defined conjugated polymers, with an emphasis on understanding the impact of sequence control along the polymer backbone. In addition, he is synthesizing new classes of cationic polymers derived from heavier main-group elements (e.g. phosphorus). 


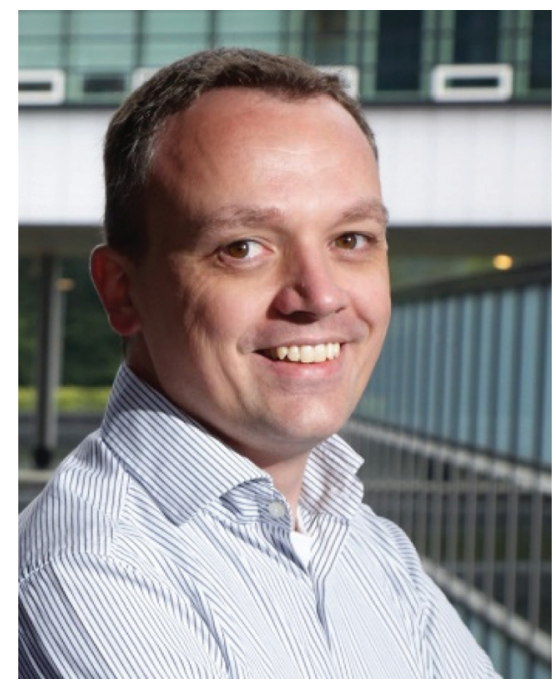

\section{Jos Paulusse}

Jos M. J. Paulusse graduated from Eindhoven University of Technology in 2002, after which he obtained his PhD degree under the supervision of Prof. Rint P. Sijbesma and Prof. Bert Meijer on the reversible mechanochemistry of coordination polymers in 2006. He worked as a postdoctoral fellow under the guidance of Prof. Craig J. Hawker at UC Santa Barbara, California. Subsequently, he joined Wageningen University as an Assistant Professor in 2009, investigating the surface modification of inorganic (nano)materials. He continued his career at the University of Twente in 2012 as an Assistant Professor and later as an Associate Professor in the Department of Biomolecular Nanotechnology. $\mathrm{He}$ is co-founder of Spectris-dot, which commercializes fluorescent silicon quantum dots. His research interests focus on the development of nanomaterials for applications in therapeutics delivery and targeted imaging, in particular well-defined, size-con- trolled polymer nanoparticles and silicon-based nanoparticles for hyperpolarization MRI.

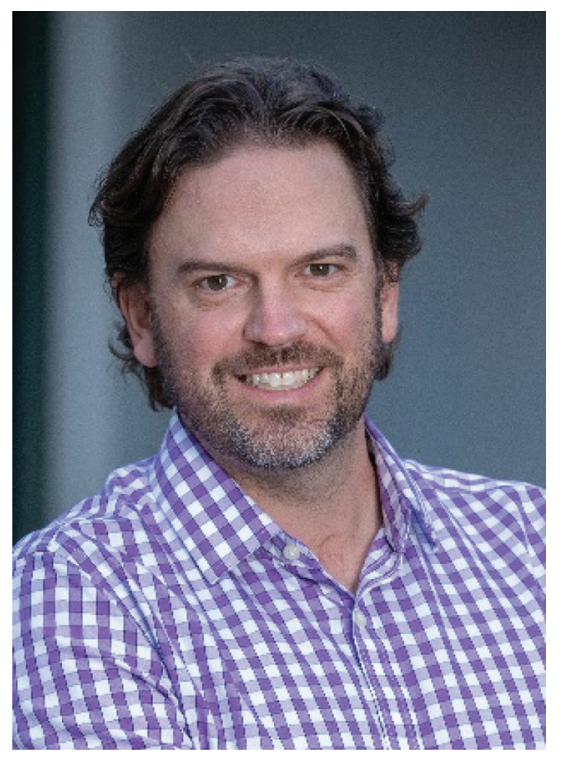

\section{Jon Pokorski}

Professor Pokorski began his career by earning his B.S. in biochemistry from UCLA, while working in private industry designing biomedical devices. Dr Pokorski received his $\mathrm{PhD}$ in chemistry from Northwestern University, where he designed peptidomimetics for use in medical diagnostics and therapeutics. Dr Pokorski then moved to The Scripps Research Institute as a post-doctoral fellow, where he engineered viral nanoparticles as drug-delivery systems. Pokorski's laboratory at UCSD works to bridge chemical synthesis, molecular biology, and materials science to make new materials for biomedical applications. The Pokorski lab is particularly interested in marrying protein and polymer science to generate materials for drug delivery and immunotherapy. Pokorski's research is funded through grants from the NIH, NSF, and ACS. He has been awarded several prestigious awards, including an ACS PRF New Investigator Award and an NIH Pathway to Independence Award. Pokorski currently serves as an IRG lead for the UC San Diego MRSEC.

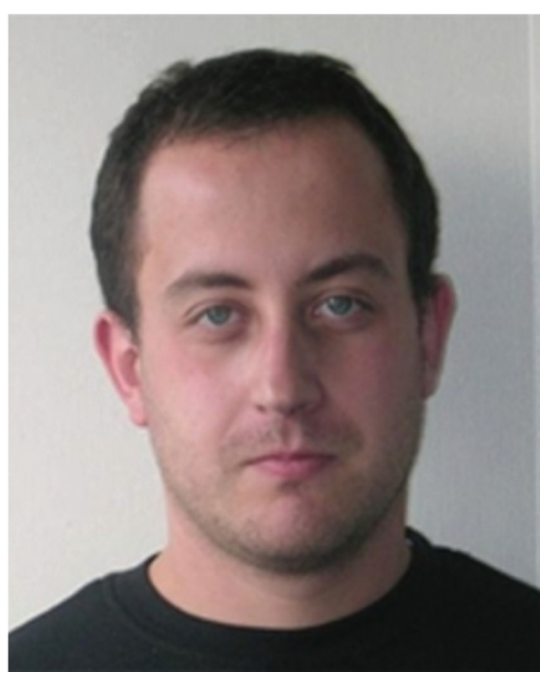

\section{Jean-Marie Raquez}

Prof. Jean-Marie Raquez, senior FRS-FNRS research associate, is the head of the Laboratory of Polymer and Composite Materials (LPCM) at University of Mons in Belgium (see http://smpc2017.blue-horizon.be/ for details) and scientific leader at the applied research center Materia Nova in Belgium. The main research areas range from controlled and catalyzed polymerization reactions to the production of high performance nanocomposites/nanohybrids via reactive processing, e.g. reactive extrusion, with a special emphasis on biobased plastics with key properties including shape-memory polymers and self-healing materials. He is author of about 170 peer-reviewed publications, 11 patents, and 6 book chapters. 


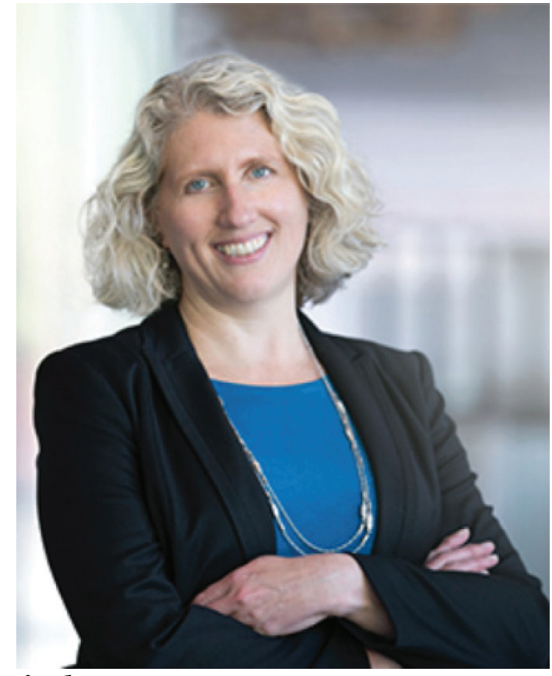

Nicole Sampson

Nicole S. Sampson received her education and training as a chemist and chemical biologist from Harvey Mudd College (BS), the University of CaliforniaBerkeley (PhD), and Harvard University (postdoctoral fellow). She is currently Distinguished Professor of Chemistry and Dean of the College of Arts and Sciences at Stony Brook University. She is a Fellow of the American Chemical Society. Her research interests include the design of chemical probes of mammalian fertilization and exploiting metabolic pathways that enable survival of Mycobacterium tuberculosis for drug discovery. Her work with polymers in fertilization led to the development of new methodology for the synthesis of alternating copolymers by ring-opening metathesis polymerization from 1-substituted cyclobutenes and unstrained cycloalkenes.

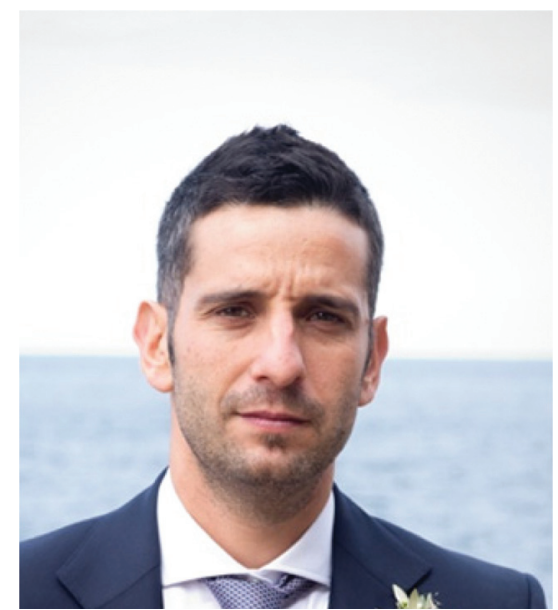

Haritz Sardon
Haritz Sardon received his Ph.D. in 2011 at the University of Basque Country under the supervision of Prof. Lourdes Irusta and Prof. M. J. Fernandez-Berridi before joining the group of Dr James Hedrick at the IBM-Almaden Research Center, USA, as a post-doc. In 2014, Haritz returned to Spain with a Ministry grant and joined the POLYMAT institute as a junior group leader before starting his independent research career as an Associate Professor at the University of Basque Country in 2017. He has published over 100 articles and his group intends to design the plastics of the future by implementing scalable and environmentally benign plastic recycling approaches and designing new polymers with not only competitive mechanical properties but also consideration of their end-of-life assessment.

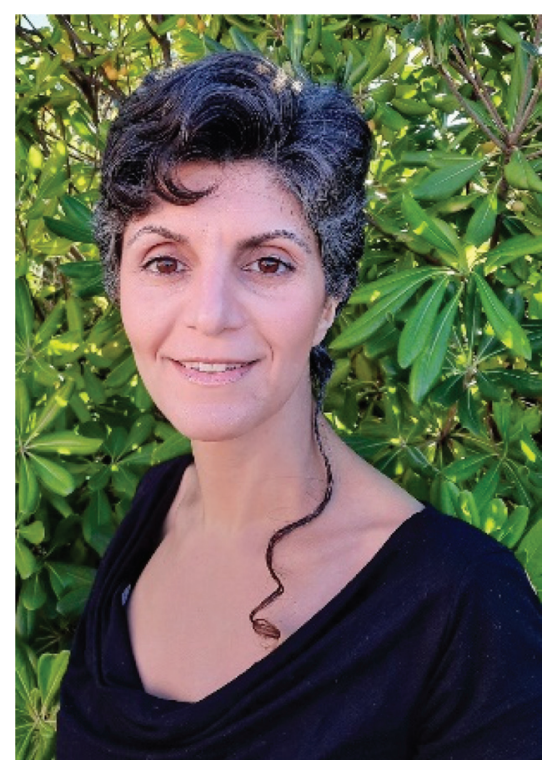

Mona Semsarilar

Mona Semsarilar earned her Ph.D. from the University of Sydney in 2010 under the supervision of Prof. S. Perrier. She then moved to the University of Sheffield (UK) to work on polymerization induced selfassembly (PISA) under the supervision of Prof. S. Armes (FRS). In 2015 she was recruited by the French national research organization (CNRS) as a research scientist based in the European Institute of Membranes (IEM) in Montpellier (France). In 2019, she received her habilitation from the University of Montpellier. Her research focuses on using synthetic chemistry to tailor molecular design and controlled self-assembly to prepare porous materials for membrane applications.

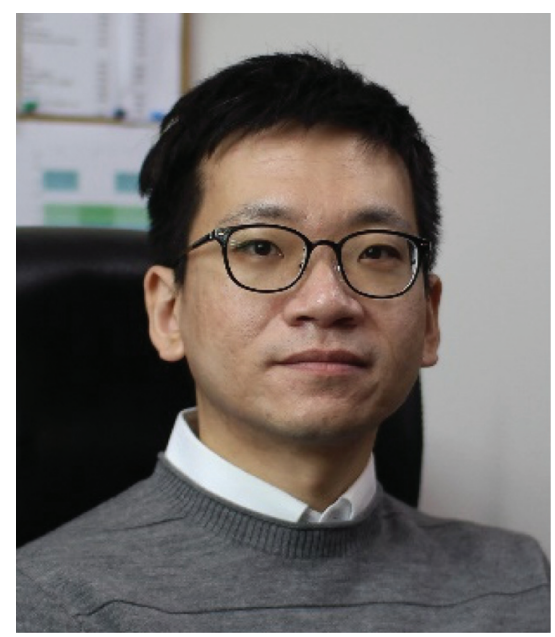

\section{Myungeun Seo}

Myungeun Seo is a polymer chemist interested in controlled polymer synthesis, polymer/small molecule self-assembly, and porous polymers for environmental and energy applications. He received his Ph.D. from the Department of Chemistry at KAIST (Korea Advanced Institute of Science and Technology) under the supervision of Prof. Sang Youl Kim (2008). He spent one year as a postdoctoral fellow in the same group and then moved to Prof. Marc A. Hillmyer's group at the University of Minnesota (2009-2013). He started his own career in 2013 at KAIST, and is now an associate professor in the Department of Chemistry. $\mathrm{He}$ is one of the editors of Macromolecular Research, and also serves Macromolecules and Chemical Physics Reviews as a member of the Editorial Advisory Boards. 


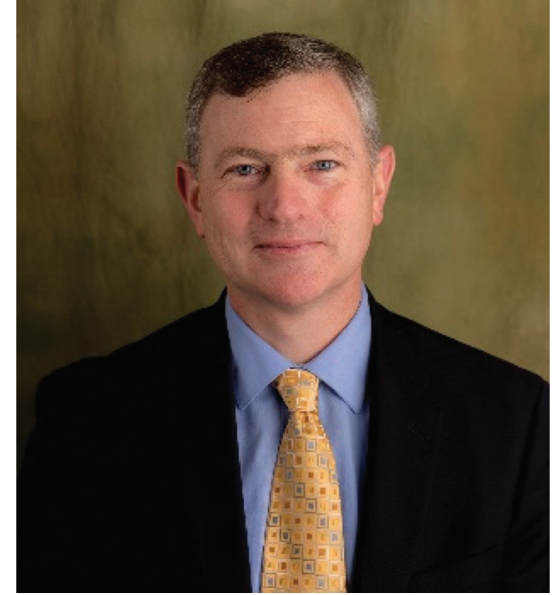

\section{Devon A. Shipp}

Prof. Devon A. Shipp completed a B. Sc. (Hons) in chemistry (1993), and then a Ph.D. (1998) at the University of Melbourne (Australia). $\mathrm{He}$ then accepted the Bayer Postdoctoral Research Fellowship at Carnegie Mellon University (Pittsburgh, Pennsylvania) with Prof. Kris Matyjaszewski. In 1999, he began his independent research career at Clarkson University in northern New York State where he is currently a full Professor in the Department of Chemistry \& Biomolecular Science and Director of Clarkson's Center for Advanced Materials Processing. His research group focuses on new polymer chemistries, particularly radical polymerizations, shape-memory polymers, selfhealing polymers, polymer nanocomposites and degradable polymers for bio-related applications. He was a Fulbright Scholar in Slovenia in 2015, hosted by the Slovenian National Institute of Chemistry and the Faculty of Chemistry and Chemical Technology at the University of Ljubljana. His website URL is: http://www.clarkson. edu/people/devon-shipp.

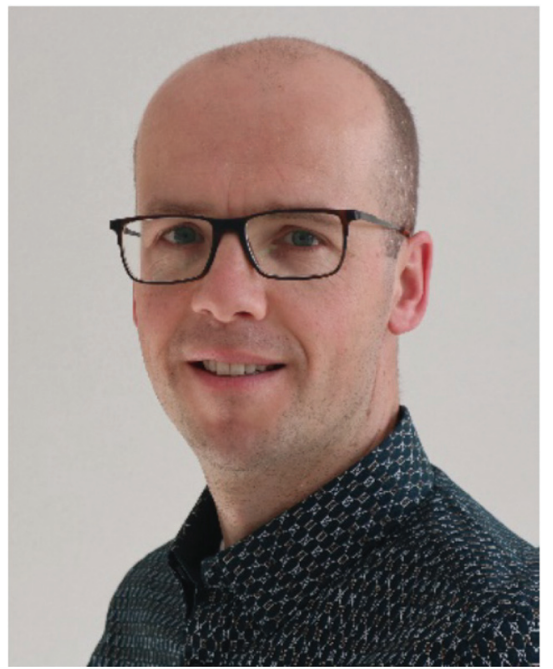

\section{Maarten Smulders}

Maarten Smulders received his $\mathrm{PhD}$ degree from the Eindhoven University of Technology (NL) in 2009, for research under supervision of Prof. Bert Meijer. After postdoctoral positions at the University of Cambridge (UK) and University of Twente (NL), he started his independent career in 2013 as assistant professor at Wageningen University (NL), where he became associate professor in 2019. His main research interests are in the development of responsive polymer coatings, and in the creation of new (design strategies for) functional covalent adaptable networks (CANs). In the latter area, he achieves control over CAN design by amplifying the control over molecular components and exchange processes to the macroscopic, material level.

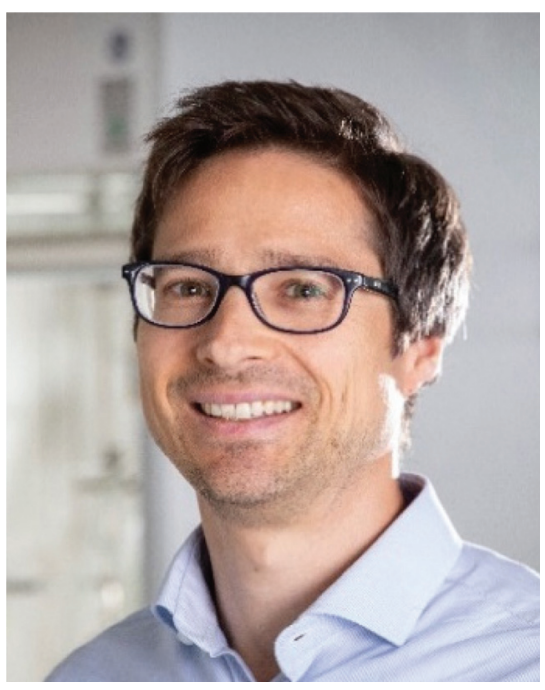

Michael Sommer

Michael Sommer is Professor for Polymer Chemistry at Chemnitz University of Technology (CUT), where he is currently Managing Director of the Institute for Chemistry. Michael studied chemistry at the Universidad de Granada, Spain, and the University of Bayreuth, Germany. With a PhD from Bayreuth in Macromolecular Chemistry, in 2009 he went to Cambridge, UK, for a two year postdoctoral stay with W. T. S. Huck. In 2012 he returned to Freiburg, Germany, to work on his habilitation between 2012 and 2016. Since 2017 he has been a full professor at CUT. His research interests encompass all kinds of conjugated polymers and materials for energy conversion and storage, functional membranes and smart materials. 


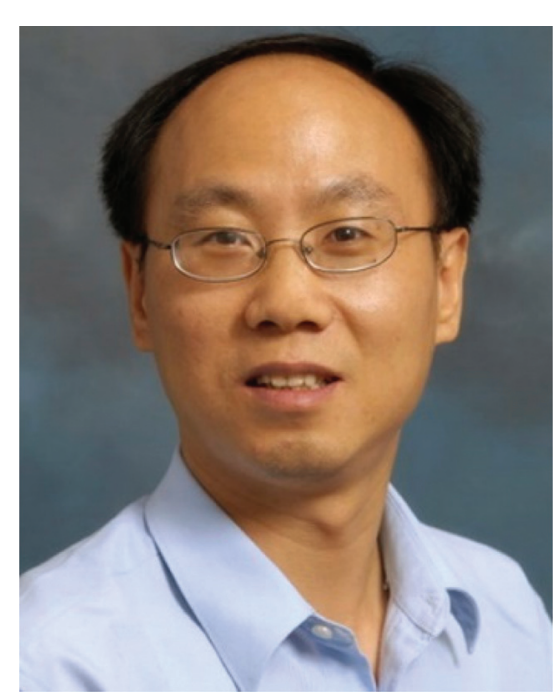

Chuanbing Tang

Dr Chuanbing Tang received his B. S. from Nanjing University, and his $\mathbf{M}$. S. and Ph.D. from Carnegie Mellon University, and did his postdoctoral research at the University of California Santa Barbara. Currently he is a distinguished professor at the University of South Carolina. His research interests focus on organic polymer synthesis, biobased polymers, metallopolymers, and polymers for biomedical and energy applications. He is a recipient of the Presidential Early Career Award for Scientists and Engineers, South Carolina Governor's Young Scientist Award, and an NSF Career Award. He is a Fellow of the Royal Society of Chemistry, an ACS POLY Fellow, and a Kavli Fellow of the National Academy of Sciences. He is an editor of Polymer and an Advisory Board member of major polymer jour- nals. He has edited one book, and published over 150 papers and 15 patents.

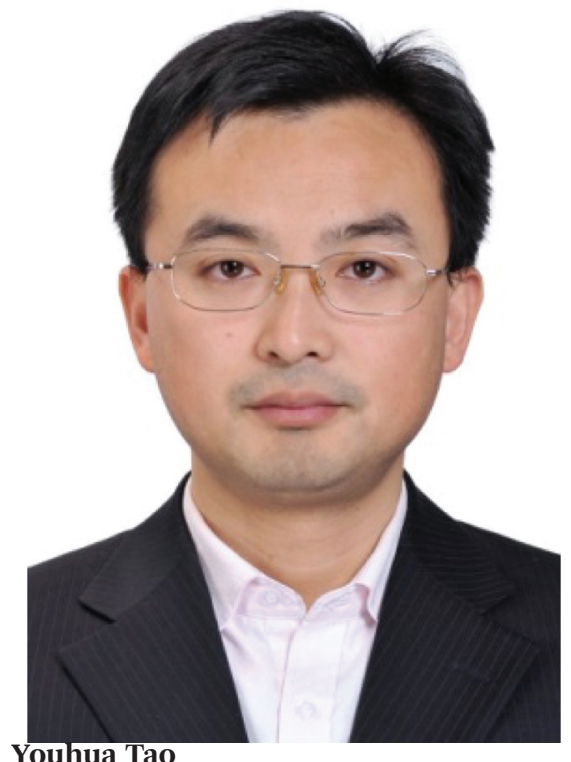

Prof. Youhua Tao received his Ph.D. in polymer chemistry in 2008 from the Changchun Institute of Applied Chemistry, Chinese Academy of Sciences, under the direction of Professor Xianhong Wang. After postdoctoral stays (2008-2013) with Professor Masami Kamigaito (Nagoya University, Japan) and Professor Christopher N. Bowman (University of Colorado at Boulder, USA), he accepted a full professor appointment at the Changchun Institute of Applied Chemistry, Chinese Academy of Sciences. His research focuses on sustainable and recyclable polymers, and organocatalytic ringopening polymerization.

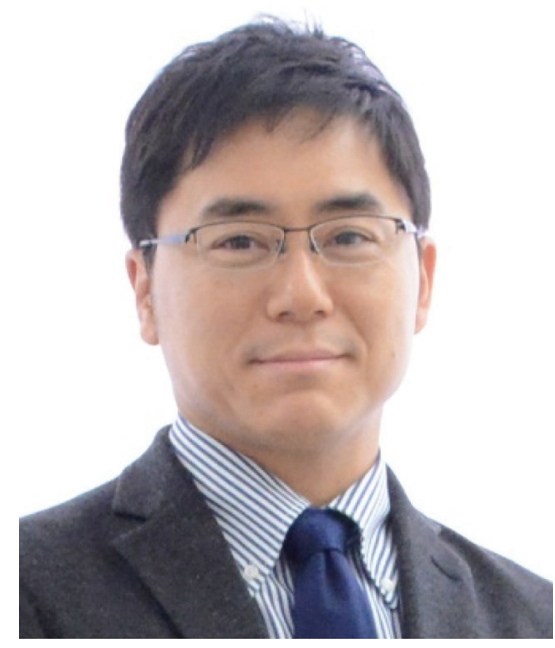

Takaya Terashima

Takaya Terashima was born in Japan (1978) and received his B.S. (2002), M.S. (2004) and Ph.D. degrees (2007) from Kyoto University under the direction of Professor Mitsuo Sawamoto. He joined the faculty of the Department of Polymer Chemistry, Graduate School of Engineering, Kyoto University in 2007 as an assistant professor and was promoted to associate professor in 2018. He also worked at Eindhoven University of Technology as a visiting researcher (2009-2010). He received the Inoue Research Award for Young Scientists (2009), the Award for Encouragement of Research in Polymer Science (2012) from SPSJ, the CSJ Special Lecture Award for Young Scientists (2012), the PJ ZEON Award for Outstanding Papers in Polymer Journal 2016 (2016) and The Young Scientists' Prize from The Commendation for Science and Technology by the Minister of 
Education, Culture, Sports, Science and Technology (2016). His research interests are precision polymer synthesis, controlled self-assembly systems, and functional polymer materials.

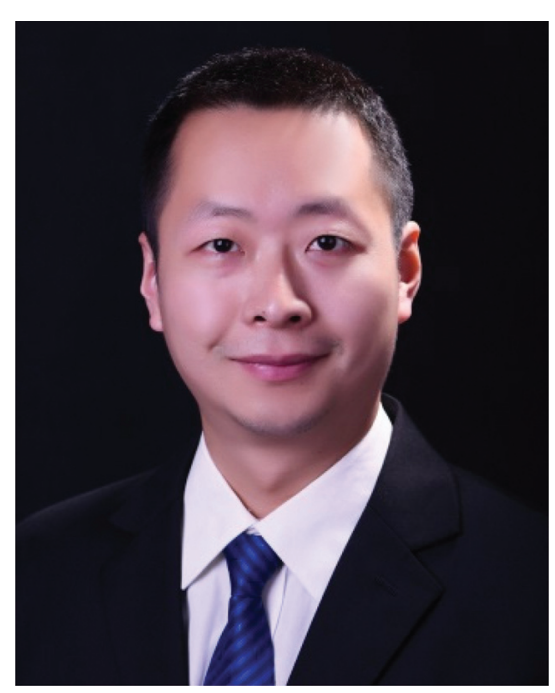

\section{Wei Tian}

Wei Tian completed his $\mathrm{PhD}$ in Polymer Materials at Northwestern Polytechnical University in 2009 under the supervision of Professor Xiaodong Fan. He pursued his research work on Polymer Chemistry as a post-doctoral researcher at the same university till 2010. Following academic appointments at Northwestern Polytechnical University, he joined the Department of Industrial and Systems Engineering at The Hong Kong Polytechnic University as a Research Associate. He came back to Northwestern Polytechnical University in 2011, and became a full professor in 2014. His scientific interests focus on hyperbranched polymers and supramolecular self-assembly.

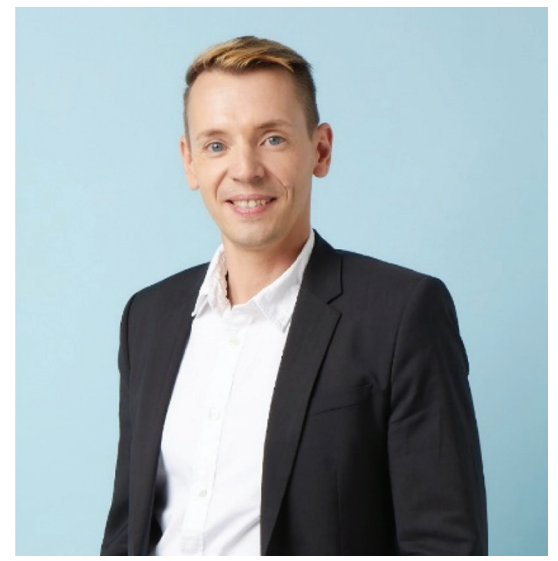

\section{Frederik Wurm}

Frederik R. Wurm is currently leading the group "Sustainable Polymer Chemistry" at the Universiteit Twente (UT, Enschede, the Netherlands). The group designs materials with moleculardefined functions for degradable polymers and nanocarriers for agricultural or biomedical applications and especially phosphorus-based polymers. He received his Ph.D. in 2009 (Johannes Gutenberg-Universität Mainz, Germany). After a two year stay at École Polytechnique Fédérale de Lausanne (Switzerland) as a Humboldt fellow, he joined the Max Planck Institute for Polymer Research (Mainz, Germany) and finished his habilitation in macromolecular chemistry in 2016. In August
2020, he was appointed as a full professor at UT.

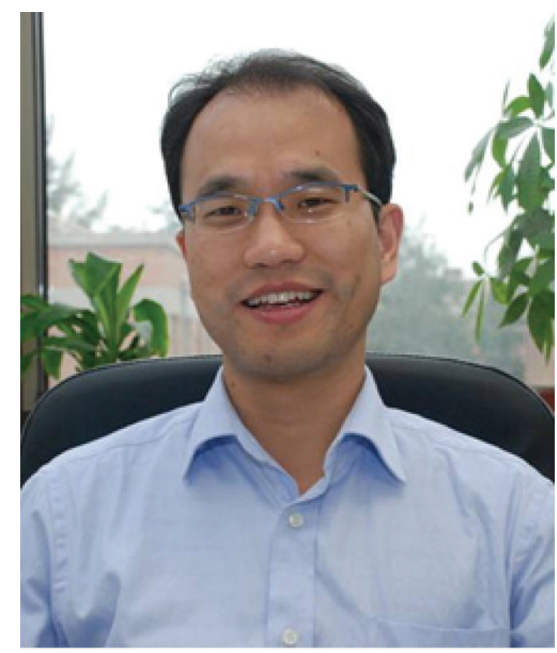

Huaping Xu

Huaping $\mathrm{Xu}$ received his Bachelors degree in 2001 and his Ph.D. degree in 2006 from Jilin University, China, under the supervision of Prof. Xi Zhang. In 2006, he joined Prof. David N. Reinhoudt and Prof. Jurriaan Huskens's group at University of Twente, the Netherlands as a post-doc. Since July 2008, he has worked in the Department of Chemistry, Tsinghua University, China. He was promoted to full professor in 2014. In 2014, he received the Natural Science Fund for Outstanding Young Scholars from NSFC. He is an Associate Editor of ACS Biomaterials Science \& Engineering. His current research is focused on selenium/tellurium-containing polymers. 


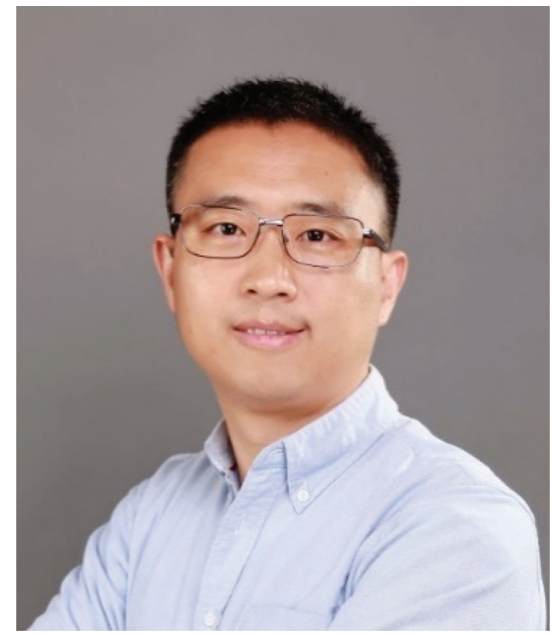

\section{Jiangtao Xu}

Dr Jiangtao $\mathrm{Xu}$ is an ARC Future Fellow and Senior Lecturer in the School of Chemical Engineering at UNSW Sydney. He is currently leading a research group in the Centre for Advanced Macromolecular Design (CAMD) and Australian Centre for Nanomedicine (ACN), with a research focus on green and precision polymer synthesis using state-of-the-art polymerization techniques and organic chemistry tools. He has more than 100 peerreviewed publications in high-impact journals, over 6000 citations and an $\mathrm{H}$-index of 44. His research areas of interest are green chemistry and sustainable polymer synthesis, precision polymer synthesis, advanced polymer materials for nanomedicine and bioengineering applications.

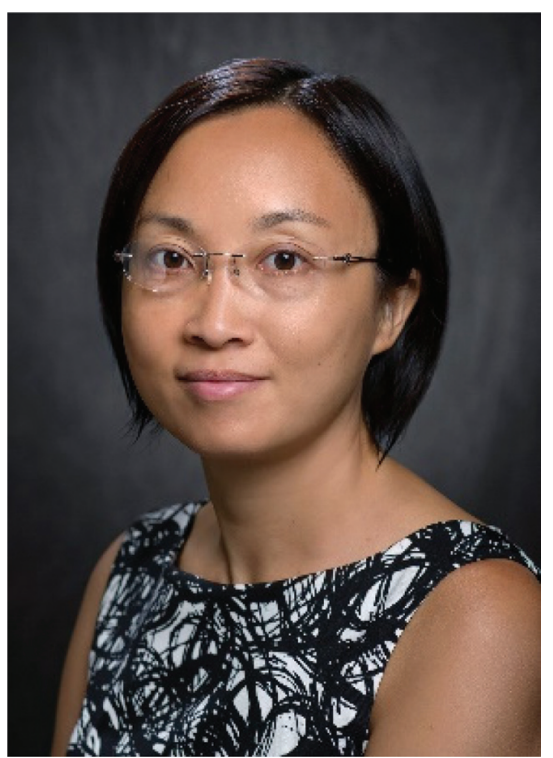

\section{Donghui Zhang}

Donghui Zhang is a Professor of Chemistry at the Louisiana State University (LSU). She obtained a B.S. degree in Chemistry from Peking University (1998) and a Ph.D. in Organometallic Chemistry from Dartmouth College (2003), and conducted postdoctoral research on the synthesis and characterization of sustainable polymers at University of Minnesota. She joined LSU in 2007 after a stint as research faculty at New Mexico State University. Her research interests include polymerization method development, synthesis and investigation of the structure-property relationship of biomimetic and bioderived polymers and high precision macromolecules. She enjoys outdoor activities and spending time with her family and friends.

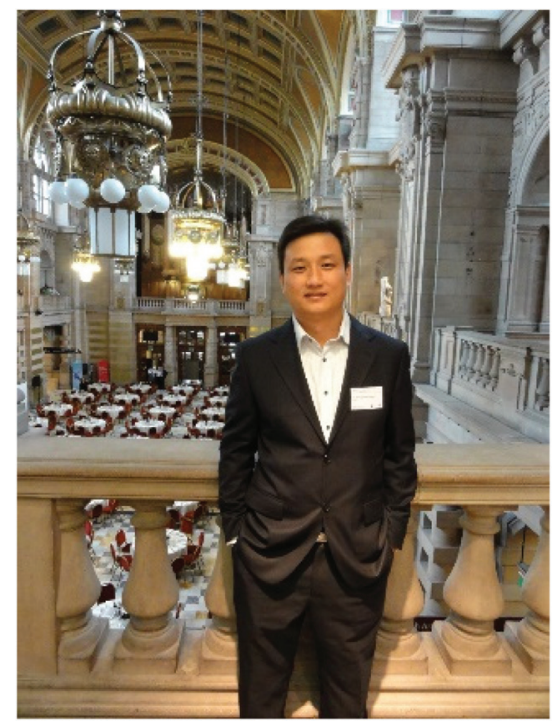

Zhengbiao Zhang

Zhengbiao Zhang received his BS degree in 2000 and his $\mathrm{PhD}$ degree in 2007 from Soochow University under the supervision of Professor Xiulin Zhu. Since 2000, he has worked as an Assistant Professor (2000), Lecturer (2003), Associate Professor (2009) and Professor (2013, current position) at Soochow University. His Postdoctoral Fellowship was in the Department of Chemical and Biomolecular Engineering of the National University of Singapore in 2007-2008 (one year) under the supervision of Professor E. T. Kang. In 2012-2013, he was appointed as a Visiting Scholar for one year in Professor 
Stephen Z. D. Cheng's group, Department of Polymer Science and Engineering, The University of Akron. In June-August 2015, he worked as a Visiting Professor with Professor Masami Kamigaito in the Graduate School of Engineering, Department of Applied Chemistry, Nagoya University. His current research interests include the precision synthesis of polymers with well-defined molecular weight, architecture, tacticity and sequence; structure/ property (function) relationships of precision polymers; recyclable and biomimetic polymers; and design and synthesis of functional polymers.

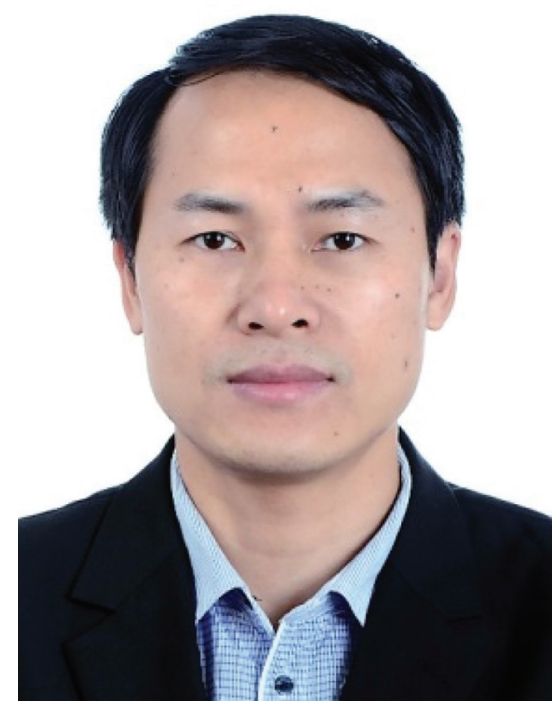

Yongfeng Zhou
Yongfeng Zhou completed his B.Sc. and M.Sc. degrees in Chemistry at Harbin Institute of Technology. In 2005, he obtained his Ph.D. degree in Polymer Chemistry and Physics at Shanghai Jiao Tong University under the supervision of Prof. Deyue Yan. Then, he joined the same university as an associate professor to start his independent research career. In 2010 , he was promoted to a full professor there. His current research interests include the controllable synthesis, self-assembly, computer simulation and cytomimetic application of amphiphilic hyperbranched polymers or alternating copolymers.

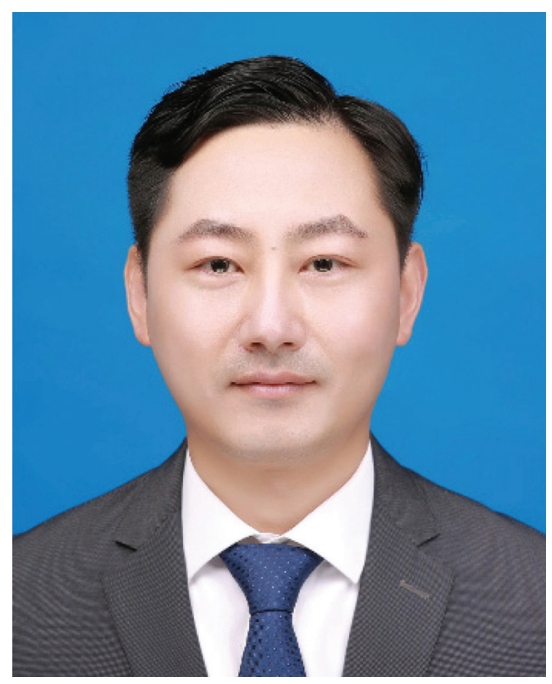

Jintao Zhu
Jintao Zhu received his Ph.D. degree from Changchun Institute of Applied Chemistry, Chinese Academy of Sciences. He then worked as a postdoctoral research fellow at the University of Alberta and the University of Massachusetts Amherst. Since 2009, he has been appointed as a professor at the School of Chemistry and Chemical Engineering, HUST. Dr Zhu is serving as an editor of Macromolecular Research. His current interests involve selfassembled polymers and nanoparticles for responsive nanophotonics, healing materials, memory devices, and immunotherapy. Dr Zhu is a Fellow of the Royal Society of Chemistry (2020), and a recipient of the China National Fund for Distinguished Young Scholars (2015), and a Chinese Chemical Society Youth Award (2013). 